\title{
A feasibility study on process monitoring and control in vat photopolymerization of ceramics
}

\section{Citation for published version (APA):}

Hafkamp, T., van Baars, G., de Jager, B., \& Etman, P. (2018). A feasibility study on process monitoring and control in vat photopolymerization of ceramics. Mechatronics, 56, 220-241.

https://doi.org/10.1016/j.mechatronics.2018.02.006

\section{Document license:}

TAVERNE

DOI:

10.1016/j.mechatronics.2018.02.006

Document status and date:

Published: 01/12/2018

\section{Document Version:}

Publisher's PDF, also known as Version of Record (includes final page, issue and volume numbers)

\section{Please check the document version of this publication:}

- A submitted manuscript is the version of the article upon submission and before peer-review. There can be important differences between the submitted version and the official published version of record. People interested in the research are advised to contact the author for the final version of the publication, or visit the $\mathrm{DOI}$ to the publisher's website.

- The final author version and the galley proof are versions of the publication after peer review.

- The final published version features the final layout of the paper including the volume, issue and page numbers.

Link to publication

\section{General rights}

Copyright and moral rights for the publications made accessible in the public portal are retained by the authors and/or other copyright owners and it is a condition of accessing publications that users recognise and abide by the legal requirements associated with these rights.

- Users may download and print one copy of any publication from the public portal for the purpose of private study or research.

- You may not further distribute the material or use it for any profit-making activity or commercial gain

- You may freely distribute the URL identifying the publication in the public portal.

If the publication is distributed under the terms of Article 25fa of the Dutch Copyright Act, indicated by the "Taverne" license above, please follow below link for the End User Agreement:

www.tue.nl/taverne

Take down policy

If you believe that this document breaches copyright please contact us at:

openaccess@tue.nl

providing details and we will investigate your claim. 


\title{
A feasibility study on process monitoring and control in vat photopolymerization of ceramics ${ }^{\text {ht }}$
}

\author{
Thomas Hafkamp, ${ }^{* a, b}$, Gregor van Baars ${ }^{\mathrm{b}}$, Bram de Jager ${ }^{\mathrm{a}}$, Pascal Etman ${ }^{\mathrm{a}}$ \\ ${ }^{\text {a }}$ Department of Mechanical Engineering, Eindhoven University of Technology, Eindhoven, The Netherlands \\ ${ }^{\mathrm{b}}$ Department Equipment for Additive Manufacturing, TNO, Eindhoven, The Netherlands
}

\section{A R T I C L E I N F O}

\section{Keywords:}

Additive manufacturing

Ceramics

Vat photopolymerization

Stereolithography

Process monitoring

Process control

\begin{abstract}
A B S T R A C T
Vat photopolymerization is a prominent additive manufacturing technology for the fabrication of near-net shape ceramic parts. To serve the high tech industry's needs, additive manufacturing equipment has to scale up to larger product sizes and higher, repeatable product quality. This motivates the integration of more process monitoring and control solutions into the equipment. Hence, this paper reviews the state of the art in process modelling, sensing, actuation and control for ceramic vat photopolymerization. The aim is to analyze the feasibility of potential real-time control schemes for the vat photopolymerization process. A comparison of time scales related to physical phenomena in vat photopolymerization, sampling rates of sensors, and response times of actuators, shows that feasibility of real-time control is governed by sensor sampling rates. With the current state of sensor technology, real-time control is only feasible in mask projection systems. Alternatively, one can resort to layer-to-layer control schemes.
\end{abstract}

\section{Introduction}

Technical ceramics for high-performance applications can be fabricated through at least seventy manufacturing techniques [1]. Most ceramic manufacturing techniques process ceramics in powder form. An alternative for the powder processing route is polymer-derived ceramics [2]. In polymer-derived ceramics, polymers acting as a precursor are transformed into ceramic components upon heat treatment. These so-called preceramic polymers can be shaped using virtually any of the conventional polymer-forming techniques such as injection molding [2]. Recently, additive manufacturing (AM) techniques are increasingly being used to fabricate near-net shape three-dimensional ceramic parts [3-5]. According to ASTM/ISO standards, these AM technologies can be classified into seven categories based on commonality in machine architecture and material transformation physics [6]. All seven AM categories can be used to produce ceramics. One of the most prominent process categories [7] is vat photopolymerization (VP), also widely known as stereolithography [8].

Like any manufacturing process, AM processes involve a complex, coupled geometry and material property transformation. The objective of any process is to have a highly repeatable product quality at high flexibility and productivity [10]. AM is a highly flexible manufacturing technology as it poses few restrictions on the geometric complexity.
However, the current lack of repeatable product quality, productivity and scalability, hinders the widespread adoption of AM. The advancement of AM technology calls for a systems engineering approach to address these integral challenges in the development of novel equipment concepts. For AM of ceramics specifically, the main challenges are to increase the density of the monolithic part, to increase the ceramic product sizes (large area) and wall thicknesses, and to avoid crack formation [5].

The need for modelling, sensing and control of AM processes is commonly recognized as crucial to the advancement of AM technology [11]. Although control systems have always been a fundamental part of any AM machine, the actual manufacturing process, i.e., the material and geometry transformation, is often still controlled in an open-loop fashion. In most AM equipment closed-loop control is limited to individual machine functions such as motion control or process parameter control, which only indirectly influence the actual process output [10]. The disturbances due to these process-independent machine state variables [12] are generally considered small compared to process variables that directly affect the quality of the output [13]. Therefore, this paper focuses on control schemes that close the loop on the actual process output.

This paper reviews the state of the art in process modelling, sensing, actuation and control for vat photopolymerization of ceramics. The aim

\footnotetext{
it This paper was recommended for publication by Associate Editor Kira Barton.

* Corresponding author at: Department of Mechanical Engineering, Eindhoven University of Technology, Eindhoven, The Netherlands.

E-mail addresses: t.m.hafkamp@tue.nl, thomashafkamp@me.com (T. Hafkamp).
} 


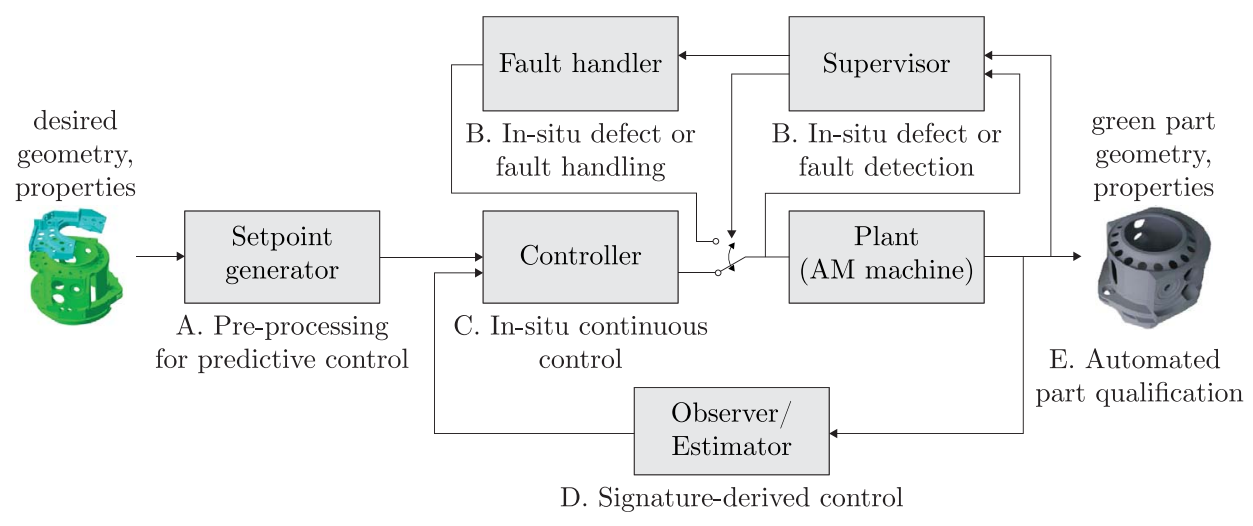

Fig. 1. Potential AM control strategy classification scheme, based on [9].

of this paper is to identify potential control strategies and analyze their feasibility. The classification scheme for potential AM control strategies by NIST [9] shown in Fig. 1 allows for positioning novel control approaches in the AM landscape, both for metal-based [14] and polymerbased [15] AM. The intended application area is in AM using ceramicfilled resins, occasionally an excursion to pure (non-ceramic) photopolymer resins is made when this is relevant for the discussion. The paper is based on literature presented in open academic journals and conferences. The paper focuses on real-time (in-situ continuous) control of the vat photopolymerization process for AM of ceramics.

The outline of this paper is as follows. This paper starts with a description of the ceramic vat photopolymerization system in Section 2. Subsequently, Section 3 gives an overview of relevant process models from literature followed by an overview of actuators and sensors in Section 4. Section 5 then reviews current control schemes in vat photopolymerization. Finally, Section 6 discusses the feasibility of control strategies and the paper offers concluding remarks in Section 7.

\section{System description}

Vat photopolymerization is a rather novel technology to perform the shaping step in the complete process chain of polymer-derived ceramics. Hence, the vast expertise on the other process steps in the polymer-to-ceramic conversion from polymer-derived ceramics can be exploited [5]. On the other hand, vat photopolymerization of pure photopolymer resins is a commonly applied process. An extensive knowledge base of the vat photopolymerization process is available. However, given the demanding processing requirements, vat photopolymerization of ceramic materials faces different challenges than of pure polymeric materials.

\subsection{Process chain}

The ceramic vat photopolymerization process encompasses a complete chain of process steps $[16,17]$ from product design and raw materials to the final product, as depicted in Fig. 2. The first step is to prepare the slurry by mixing ceramic powder and photopolymer resin. In the second step, the slurry is fed into the machine. Also the build plate, i.e., the substrate onto which the part will be fabricated, is mounted. Next, the desired product geometry is uploaded to the machine and the build process is set up. In the build step the so-called "green" part is built through vat photopolymerization. The built product is still in a "green" state in which the ceramic powder is held together by cured photopolymer binder [16]. After removing excess slurry from the machine, the green part is separated from the build plate and removed from the machine. The part is cleaned and put into an oven to pyrolize the binder in a debinding step at moderate temperature. Finally, the ceramic particles are sintered at high temperature to obtain the final dense ceramic product, with associated sintering shrinkages up to $20 \%$ [18].

\subsection{Vat photopolymerization system description}

Ceramic vat photopolymerization merely replaces conventional unfilled photopolymer resins with ceramic-filled resins. However, as the ceramic filler has a significant influence on the AM build process, purpose-built machines for ceramics have been designed [7]. The main challenges due to the presence of ceramic filler arise from an increased slurry viscosity, decreased resolution due to light scattering, and sensitivity for defects during the thermal post-treatment [19]. Nevertheless, the concept of the vat photopolymerization build process is essentially the same for ceramic-filled and pure photopolymer resins: products are fabricated by selectively irradiating and consequently solidifying layers of liquid photopolymer contained in a vat [6]. Fig. 3 schematically depicts a typical vat photopolymerization system and its main subsystems.

For the vat photopolymerization system three processing steps can be distinguished [20]: preprocessing, recoating, and irradiation (or photopolymerization). The function of the preprocessing step is to convert the desired part geometry into a sequence of machine instructions stored in a build file, i.e., setpoint or reference generation.

After the build file has been transferred to the machine, the actual build process begins with recoating. The function of the recoating step is to apply a resin layer of specified thickness across the build area. To this end, first an elevator containing the build platform lowers by exactly one layer thickness. Then, a recoater device typically moves one or multiple times over the vat to deposit and recoat photopolymer resin.

Once a fresh layer of photopolymer material has been deposited, irradiation can begin. The function of the irradiation step is to perform the actual material transformation from the liquid to the solid phase through photopolymerization. To this end a light source, typically in the UV range, selectively irradiates only those parts of the vat surface that correspond to the current layer's cross-section of the product. The recoating and photopolymerization steps are repeated for each layer until the product is finished.

Recently, novel photopolymerization processing concepts have been developed, in which recoating and irradiation occur simultaneously $[21,22]$. That is, parts are photopolymerized during continuous platform movement. The printing speed is either limited by resin curing or by resin flow, depending on the cross-sectional area of the momentary slice [21]. At the time of writing, such continuous photopolymerization concepts only work for particular polymer resins specifically developed for continuous irradiation, without ceramic fillers.

Current ceramic vat photopolymerization systems lack repeatable part quality, as exemplified by [23-25]. This motivates the integration of more process monitoring and control solutions into the AM machine. A closed-loop control scheme similar to the one shown in Fig. 1 can be envisioned for the photopolymerization step. The desired process trajectories, i.e., the references or setpoints, are generated by the preprocessor from the desired product geometry and properties. The 


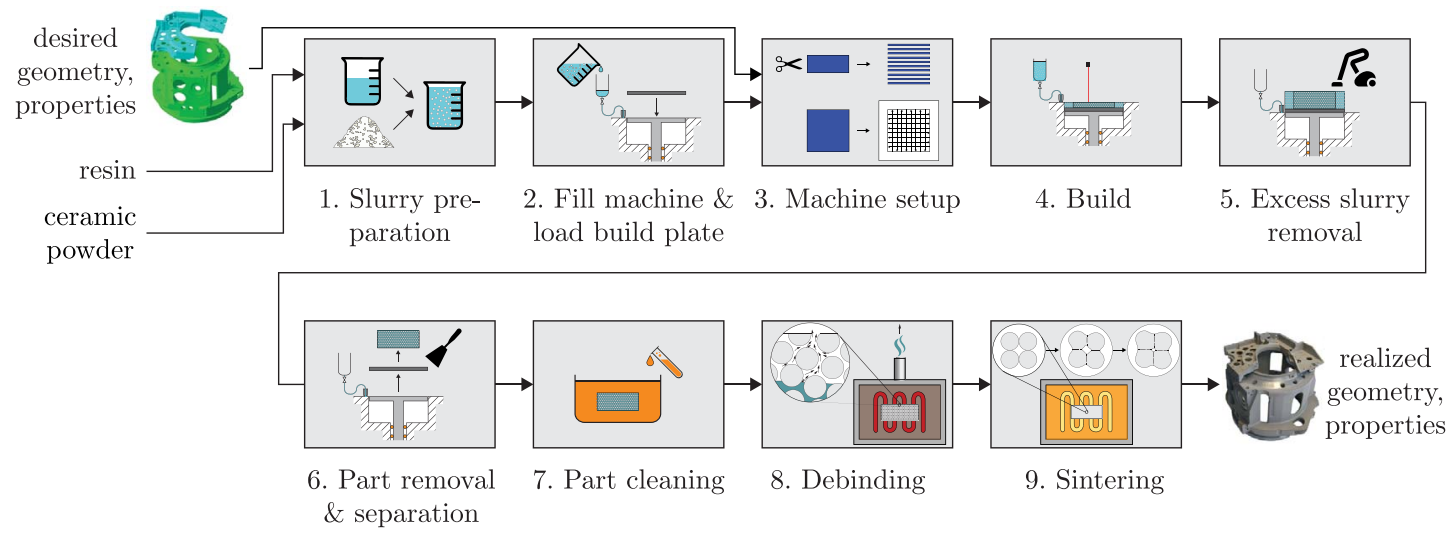

Fig. 2. Ceramic vat photopolymerization process chain.

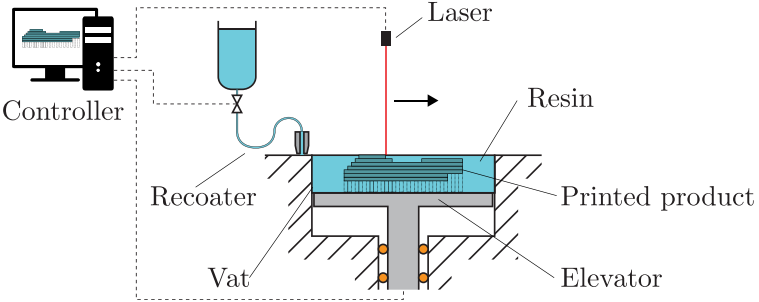

Fig. 3. Vat photopolymerization system main subsystems.

process controller computes machine inputs that are sent to the actuator, i.e., the laser. The laser starts to irradiate the photopolymer and consequently the process, photopolymerization, takes place. The actuator and photopolymerization process together form the plant, whose outputs are the realized process trajectories. These realized trajectories may differ from the reference trajectories. To close the loop one or more of the process outputs need to be measured by a sensor. Subtraction of the measured trajectory from the reference trajectory (setpoint) provides for an error signal that can be fed back to the process controller. Such a closed-loop control scheme can be envisioned for both the photopolymerization and the recoating step. The scope of this paper is to survey options to realize closed-loop control of the photopolymerization process.

\section{Process modelling}

In essence, any manufacturing process involves a complex, coupled geometry and material property transformation [10]. Physics-based process models that describe this transformation are crucial to improve understanding of the process and ultimately optimize and control the process for improved part quality [14]. A general overview of photopolymerization process modelling is given in $[6,26]$. An overview of (semi-)empirical models rather than of physics-based process models is given in $[27,28]$.

A fundamental question of any process model is what the purpose of the model is. The purposes of the models reported in literature vary from merely increasing our understanding to planning and controlling the process. For in-situ continuous control of the photopolymerization process, a model is desired that describes the process dynamics under transient conditions. The model should only include those physical phenomena that are considered as relevant to the model purpose [29]. Since modelling is fundamental for control system design, this review aims to give a comprehensive overview of the phenomena reported in literature and their respective modelling.

An important assumption in most photopolymerization process models is that a perfectly flat layer of photopolymer resin or ceramic slurry has been deposited in the recoating phase. Undoubtedly, the most simple model of recoating is the addition of a perfectly flat layer.

Decomposing the photopolymerization model into two submodels for the actuation or irradiation and for the cure process itself seems a sensible choice for model modularity and was proposed in [30]. Fig. 4 shows a high level block scheme of the irradiation and cure process model.

The model inputs are the process parameters, machine properties, resin properties, and boundary conditions. The cure model outputs can comprise a multitude of outputs depending on the model purpose, but arguably the ideal outputs would be the cured geometry, the physical properties, and performance indicators such as build time. The output of the irradiation model is the irradiance $I(x, y, z, t)$ received by each point in the vat as a function of time; this enables the comparison of different irradiation methods described in Section 4.1. Note however, that a bilateral coupling can exist between the two submodels as indicated by the leftwards arrow in Fig. 4, which is the case for, e.g., photobleaching resins [31]; see Section 3.1.3. In the following sections, first the modelling of irradiation and optical phenomena is reviewed, followed by the modelling of the photopolymerization cure process.

\subsection{Irradiation phenomena}

Perhaps the most fundamental property of the laser and optics system is the spatial irradiation profile. In the laser and optics system

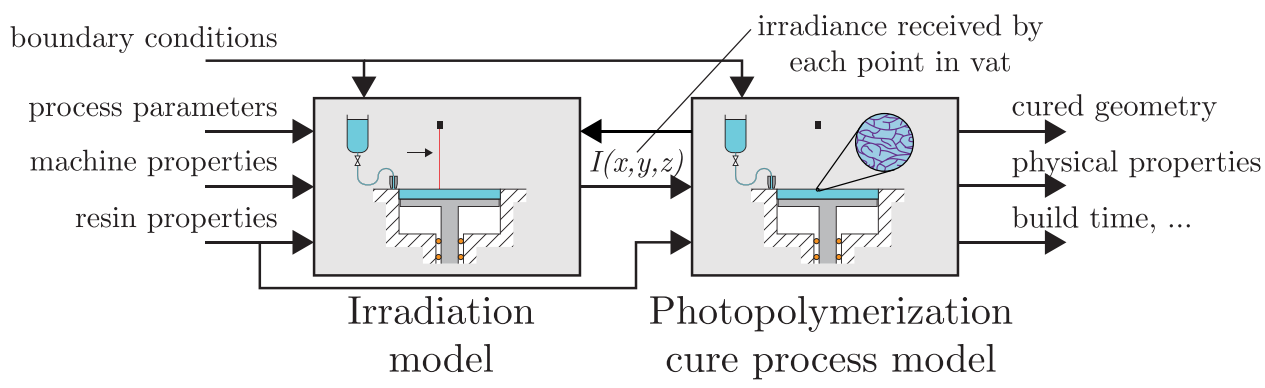

Fig. 4. Block scheme of irradiation and photopolymerization model. 


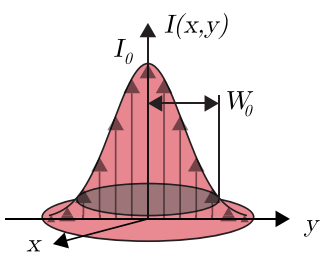

(a) beam profile

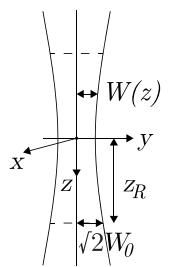

(b) beam propagation
Fig. 5. Gaussian beam.

one or more beams are generated, conditioned, shaped, and positioned or steered across the resin surface. Of interest is the resulting incident irradiance at any point in the resin $I(x, y, z)$ (in a fixed reference frame), i.e., the radiant power per unit area $\left[\mathrm{W} / \mathrm{m}^{2}\right]$. The resultant irradiance naturally depends on the irradiation method employed, the laser type, the geometry and layout of the optical components, and optical phenomena resulting from the interaction of light with matter.

\subsubsection{Irradiation profile}

Traditional vector scanning vat photopolymerization systems make use of a single Gaussian laser beam [8]. Fig. 5(a) shows a Gaussian beam profile, which is characterized by the $1 / e^{2}$ half-width or radius $W_{0}$ and the peak intensity $I_{0}$ at the beam center. The beam irradiance at a point $(x, y)$ in the focal plane of the beam is given by [6]:

$I(x, y, 0)=I_{0} e^{-\frac{2 x^{2}}{W_{0}^{2}}} e^{-\frac{2 y^{2}}{W_{0}^{2}}}, I_{0}=\frac{2 P_{L}}{\pi W_{0}^{2}}$

where $P_{L}$ is the laser output power. An ideal Gaussian beam is assumed here, but in reality the actual irradiation profile deviates from the theoretical one. Through the use of optical elements other irradiation profiles such as a top-hat, a uniform hat shaped profile, can be formed.

Mask projection vat photopolymerization systems make use of a 2D array of beams. In these systems the irradiation profile of the individual beams (pixels) can be modelled in a similar fashion as in vector scanning vat photopolymerization systems [32,33]. The projection system usually consists of a light source, a Digital Micromirror Device (DMD) and one or more lenses and mirrors. The irradiance profile of a single pixel can be modelled by a Gaussian distribution approximation of a point-spread function [32,33], i.e., an expression similar to (1). Fig. 6 shows a projection system, a top view of its individual pixels and the irradiation profile of a single pixel [33]. As Fig. 6(b) shows, the irradiation profile exceeds the boundaries of a single pixel. Hence, the light beam of a pixel will spread to its neighboring pixels, a phenomenon termed cross-talk $[32,34]$. The ratio of the Gaussian beam width $W_{0}$ and the pixel size gives a quantitative measure of the cross-talk between neighboring pixels.

The irradiation profile is an effective metric for the light intensity received by every point on the resin surface. This irradiation profile, however, is the result of light transiting an optical path from the light source via optical components to the photopolymer resin. More detailed models of the optical system can be formulated such as an analytical optics-based model of the individual components that form the light beam. Two approaches exist to modelling the optical system, namely physical optics and geometrical optics [35]. The former treats light as a wave, whereas the latter treats light as a collection of rays. Limaye developed such a geometric irradiance model for mask projection micro-stereolithography systems based on ray tracing [35]. Zyzalo later improved the Limaye model to make it suitable for large parts [36].

\subsubsection{Beam propagation}

A Gaussian beam always diverges from or converges to a point along the beam propagation axis [37]. Fig. 5(b) shows the variation of the Gaussian beam half-width $W(z)$ along the $z$-axis. The beam intensity decreases along the $z$-axis and at a distance $z_{R}$ from the focal point, i.e., the Rayleigh range, the beam half-width equals $\sqrt{2} W_{0}$ and the maximum intensity equals $\frac{1}{2} I_{0}$. In traditional vat photopolymerization systems, the machine is designed such that the focal point lies on the resin surface [20]. Although any Gaussian beam exhibits beam propagation, the only work known to the authors to explicitly include the effect in modelling the vat photopolymerization process is the model by Sager [37].

\subsubsection{Attenuation and absorption}

A fundamental phenomenon and challenge in vat photopolymerization is the attenuation of light travelling through photopolymer resin. Attenuation is the loss of radiant flux intensity due to either absorption or scattering. The result is that the irradiance at the resin surface attenuates with the distance or depth travelled through the resin. Attenuation due to absorption is described by the Beer-Lambert law [38], which states that absorbance $A$ is directly proportional to the path length $l$ and concentration $[c]$ of the attenuating species:

$A=\varepsilon[c] l=\log _{10}\left(\frac{I_{0}}{I}\right)$

where $I_{0}$ is the ingoing light intensity, $I$ is the exiting light intensity and $\varepsilon$ is the extinction coefficient or molar attenuation coefficient. Rearranging the terms in (2) and substituting $l$ for $z$ gives an expression for the irradiance as a function of depth $z$ [39]:

$I(z)=I_{0} e^{-\ln (10) \cdot \varepsilon[c] z}$

where the $\ln (10)$ term originates from the conversion from base- 10 to base-e logarithms. Note that different conventions as to whether absorbance is decadic (base-10) or Napierian (base-e) is used, so the term $\ln (10)$ is sometimes omitted. In the remainder of this paper the Napierian extinction coefficient $\varepsilon^{\prime}=\ln (10) \cdot \varepsilon$ is used.

In vat photopolymerization this expression is often written as a

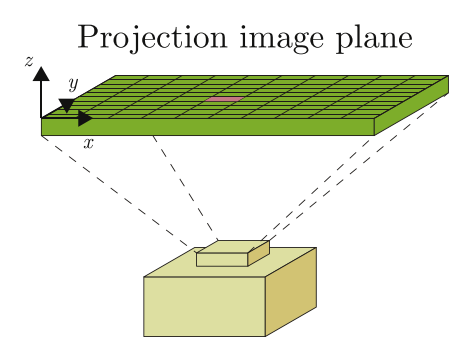

(a) projection system

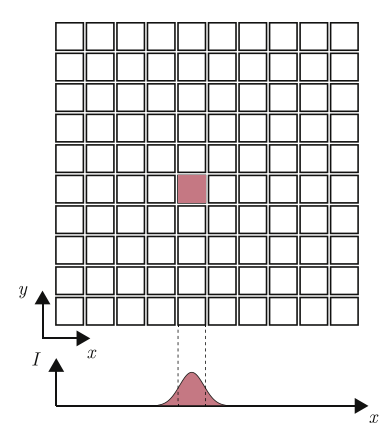

(b) top view

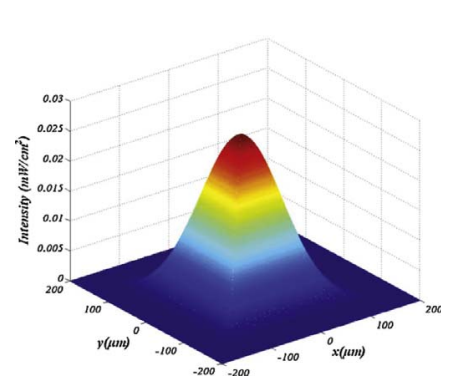

(c) single pixel

Fig. 6. Mask projection system irradiation profile; (a) and (c) adopted from [33]. 


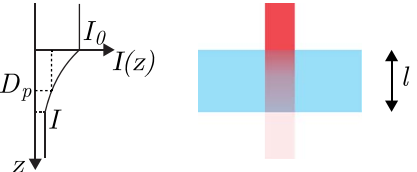

Fig. 7. Beer-Lambert absorption.

function of the penetration depth $D_{p}$, which is defined as the depth $z$ at which the irradiance has decreased to a factor $e^{-1} \approx 0.37[6,8]$, see Fig. 7:

$I(x, y, z)=I_{0} e^{-\frac{z}{D_{p}}}$

The penetration depth is related to the attenuation coefficient and concentration as follows [8]:

$D_{p}=\frac{1}{\varepsilon^{\prime}[c]}=\frac{1}{\ln (10) \cdot \varepsilon[c]} \approx \frac{1}{2.303 \cdot \varepsilon[c]}$

Fig. 7 illustrates the effect of Beer-Lambert attenuation. For photopolymers, the species of interest is the initiator so the extinction coefficient and (instantaneous) concentration of the photoinitiator is taken. In some resins additives are added such as light absorbers [40]. In this case the material consists of multiple attenuating species and then the absorbance $A$ depends on the concentrations and extinction coefficients of the individual species:

$A=l \cdot \sum_{i=1}^{N} \varepsilon_{i}\left[c_{i}\right]$

The preceding expressions for attenuation assume a uniform and constant molar attenuation coefficient and concentration along the path. During photopolymerization however, the absorbance of the photoinitiator can change upon photolysis and diffusion of reactive species can take place [39]. In photobleaching resins, the absorbance decreases during photopolymerization and as a result the irradiance is attenuated less as time proceeds [41]. In non-photobleaching resins, the Beer-Lambert law for uniform and constant species (3) suffices [39]. To model the time-varying absorbance in photobleaching resins, expressions for both the concentration $[c]$ and intensity $I$ as a function of depth $z$ need to be composed [41,42]. To this end, the differential form of the Beer-Lambert law is used [43]:

$\frac{\partial I(z)}{\partial z}=-\varepsilon^{\prime}[c](z) I(z)$

from which the Beer-Lambert law for uniform and constant absorbance (3) can be derived.

Another approach to model the difference in attenuation between cured and uncured resin was proposed by Limaye in a "transient layer cure model" [35]. For the resins used, the penetration depth of the cured part significantly differed from the penetration depth of uncured resin, i.e. the penetration depth of cured resin tended to infinity. Hence a model was developed that takes into account this difference in penetration depths.

\subsubsection{Scattering}

As described earlier, attenuation of light intensity occurs due to either absorption or scattering [31]. Scattering is an optical phenomenon in which the direction of light (radiation) is changed due to nonuniformities in the medium it is transmitted through as illustrated by Fig. 8. It is beyond the scope of this work to give a complete overview of all the modelling approaches to light scattering, but several key publications are referred to. Sun and Zhang developed a Monte Carlo raytracing technique to compute the spatial irradiance distribution and used this for a bilaterally coupled kinetic photopolymerization model through the photoinitiator concentration distribution [31,44]. Scattering can ultimately result in a decrease in vertical dimensions (cure depth) and an increase in lateral dimensions (broadening) [31].

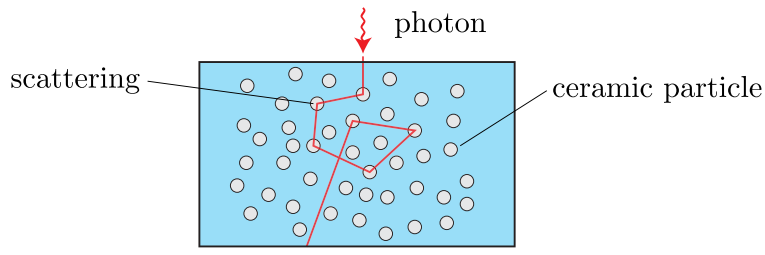

Fig. 8. Scattering due to ceramic particles, adopted from [31].

Liao gives an overview of modelling techniques of scattering in ceramic slurries for vat photopolymerization [45]. Griffith and Halloran developed an analytical expression for the effective extinction coefficient of ceramic slurries, which is equivalent to penetration depth $D_{p}$ [46]:

$D_{p}=\frac{3 \widetilde{Q} \Delta n^{2}}{2\langle d\rangle n_{0}^{2}}$

where $\widetilde{Q}$ is the scattering efficiency, $\langle d\rangle$ is average particle size, $\Delta n=n_{p}-n_{0}$ is the refractive index difference between the ceramic particle $n_{p}$ and resin $n_{0}$, and $\widetilde{Q}$ is a scattering efficiency term. A different expression for the penetration depth of ceramic slurries was developed by Tomeckova, Gentry and Halloran $[7,16,47]$.

\subsubsection{Refraction and optical self-focusing}

Refraction is an optical phenomenon in which the direction of light is changed due to a change in the medium it is transmitted through. Refraction can occur for non-zero incident angles at the vat surface, where the medium changes from air to resin, see Fig. 9(a). Sager developed a model for vector scanning vat photopolymerization that takes into account non-zero incident angles and resulting refraction, which changes the spatial irradiance distribution $I(x, y, z)$.

During photopolymerization the resin shrinks, the density increases and hence the refractive index increases as well [8]. This is the case for refraction at the interface, as shown in Fig. 9(b). Brulle et al. developed a Monte-Carlo model to simulate refraction at the solid-liquid interface [48]. Another Monte-Carlo model for the propagation of light in photopolymerization was developed by Schmocker [49].

Another effect known in photopolymerization is the optical selffocusing effect $[8,50]$. The non-homogeneous spatial irradiance distribution causes a non-homogenous spatial density and refractive index distribution. So in fact refraction could take place at any portion of the resin that is being photopolymerized and this could lead to an effect called 'self-focusing'. Jariwala developed an optical model of a mask projection system (refer to Fig. 26) to investigate the effect of optical self-focusing [50]. Jariwala concluded that the optical self-focusing effect was negligible for the shallow incident angles and small refractive index differences for the used system and resin.

\subsubsection{Beam positioning}

The expression for the irradiance distribution (1) is for the situation of a stationary beam. The ability to position the beam is essential to the system functionality and therefore modelling beam movement more closely represents the actual process [51]. To this end, a fixed reference

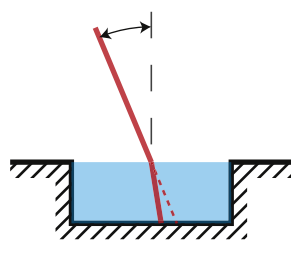

(a) at surface

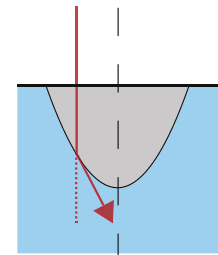

(b) at interface
Fig. 9. Refraction phenomena. 


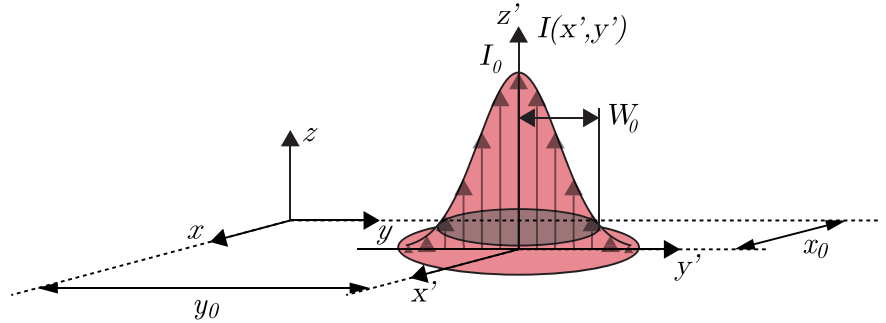

Fig. 10. Gaussian beam profile in fixed reference frame.

frame $(x, y, z)$ is defined and the original reference frame is named $\left(x^{\prime}\right.$, $\left.y^{\prime}, z^{\prime}\right)$ and is now positioned at $(x, y)=\left(x_{0}, y_{0}\right)$ as shown in Fig. 10 .

The irradiance $I(x, y, z)$ then becomes:

$I(x, y, z)=I_{0} e^{-\frac{2\left(x-x_{0}\right)^{2}}{W_{0}^{2}}} \cdot e^{-\frac{2\left(y-y_{0}\right)^{2}}{W_{0}^{2}}} \cdot e^{-\frac{z}{D_{p}}}$

The beam is positioned in the $x y$-plane by altering the values of the position coordinates $x_{0}$ and $y_{0}$.

\subsection{Photopolymerization cure process phenomena}

As discussed at the beginning of Section 3, the output of the irradiation model is the irradiance $I(x, y, z)$ received by each point in the resin vat. Upon irradiation a photoinitiated polymerization reaction takes place and the liquid resin is locally solidified. The desired outputs of a photopolymerization cure process model would be performance indicators such as the cured geometry, physical properties and build time. Due to the many physical phenomena playing a role in the reaction, models computing all these performance indicators are likely to require a high level of complexity. Before going into detail on these phenomena, a simple and insightful process model is described that enables computation of the cured shape geometry.

\subsubsection{Exposure and the exposure threshold model}

The extent of resin cure is governed by the amount of energy received rather than the power. The exposure $E$ is the time integral of irradiance $I$ and has the units of energy per unit of area $\left[\mathrm{J} / \mathrm{m}^{2}\right]$. Simple integration over time of the spatially distributed irradiance $I(x, y, z)$ gives the exposure $E(x, y, z)$. The most simple cure process model for pure resins is the exposure threshold model developed by Jacobs [8,52]. Central to the exposure threshold model is the assumption that the resin transition from the liquid to the solid phase occurs at the gel point and that the exposure threshold for the formation of gel is the critical exposure $E_{c}$.

The exposure threshold model simply states that every point in the vat for which holds that $E \geq E_{c}$ is solidified and all other points remain liquid. Assuming a flat layer of resin with constant Beer-Lambert absorption and a laser beam with a Gaussian irradiance distribution, the cured geometry can be easily calculated. This can be done numerically for an arbitrary scan trajectory $\left(x_{0}(t), y_{0}(t)\right)$ by integrating the expression for a moving Gaussian beam (9):

$$
\begin{aligned}
E(x, y, z, t) & =\int_{t} I(x, y, z, t) d t \\
& =\int_{t} I_{0} e^{-\frac{2\left(x-x_{0}(t)\right)^{2}}{W_{0}^{2}}-\frac{2\left(y-y_{0}(t)\right)^{2}}{W_{0}^{2}}-\frac{z}{D_{p}}} d t
\end{aligned}
$$

and subsequently comparing to the exposure threshold $E_{c}$. Jacobs however, derived an analytical expression for the cured line shape of a line scan along the $x$-axis. Fig. 11 visualizes the exposure threshold model for a line scan with speed $V_{s}$ along the $x$-axis. Integration of $x_{0}(t)$ from $-\infty$ to $\infty$ gives a very good approximation of the exposure received by every point in the $y z$-plane at any point along the $x$-axis $[6,8]$ :

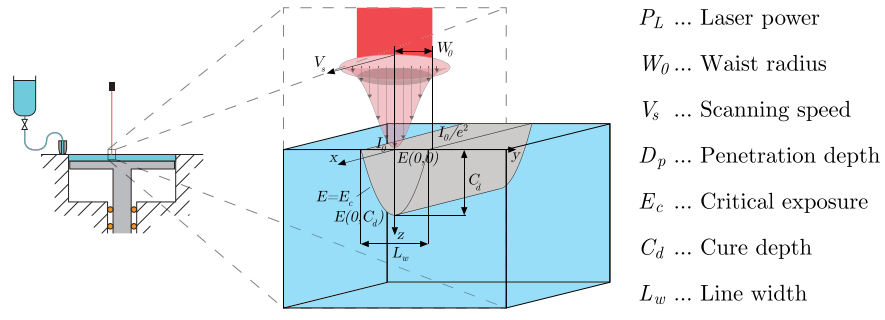

Fig. 11. Exposure threshold model for a line scan.

$E(x, y, z)=\underbrace{\frac{\sqrt{2} P_{L}}{\sqrt{\pi} V_{s} W_{0}}}_{E_{\max }} \cdot \underbrace{e^{-\frac{2 y^{2}}{W_{0}^{2}}}}_{\begin{array}{c}\text { Gaussian } \\ \text { distribution }\end{array}} \cdot \underbrace{e^{-\frac{z}{D_{p}}}}_{\begin{array}{c}\text { Beer-Lambert } \\ \text { absorption }\end{array}}$

where $E_{\max }$ is the maximum exposure, which is received on the $x$-axis at the surface.

As the figure shows, the cured line shape can be obtained by determining the locus of points at which $E=E_{c}$ from (11); this yields a parabolic shape. All the points inside the locus are solidified and all points outside the locus remain liquid. The cured line shape is characterized by two dimensions, namely the cure depth $C_{d}$ and the linewidth $L_{w}$, which are both determined from the locus of points [52]:

$C_{d}=D_{p} \ln \left(\frac{E_{\max }}{E_{c}}\right)=D_{p} \ln \left(\frac{\sqrt{2} P_{L}}{\sqrt{\pi} W_{0} V_{s} E_{c}}\right)$

$L_{w}=W_{0} \sqrt{\frac{2 C_{d}}{D_{p}}}$

By rewriting the expression (12) for laser scanning speed $V_{s}$, for a desired cure depth and given resin parameters $D_{p}, E_{c}$ and laser power $P_{L}$, the required scanning speed can be calculated [52]. Sager extended the exposure threshold model to include the effects of an incident angle, the resulting refraction and the varying beam waist $W(z)$ (see Fig. 5 (b)), and solved it using numerical simulation [37].

The exposure threshold model only holds for non-ceramic resins. The effects of scattering on the cured part shape can be considerable. Fig. 12 illustrates the effect of scattering on the cured line shape for a near top-hat irradiation profile $[7,53]$. Note that the cured linewidth can be several times wider than the incident beam itself. Empirical expressions for the cure depth and linewidth of ceramic suspensions were derived by Gentry, Tomeckova and Halloran [7,16].

Although the exposure threshold model is a simple model to determine the geometric shape of the cured part and might prove useful for control purposes, it is arguably an oversimplification of the actual photopolymerization process [54]. Fig. 13 illustrates the complexity of the photopolymerization reaction and the many physical phenomena that play a role. On the contrary, the simple exposure threshold model assumes that exposure is additive and does not take any of these phenomena into account except the phase transition from liquid to solid at the gel point.

\subsubsection{Photopolymerization cure process mechanism}

Photopolymerization is a light-initiated chemical reaction in which small molecules termed monomers are linked together or combined into larger macromolecules termed polymers [55]. The photopolymer resin is generally formulated from monomer and photoinitiator and possibly other fillers or additives, such as reactive diluents, stabilizers and ceramic particles [6]. Two resin types commercially available are acrylates on the one hand and epoxy and vinylether on the other. The accompanying cure mechanisms are free-radical polymerization and cationic polymerization respectively.

The first resins used in vat photopolymerization were acrylates and therefore free-radical photopolymerization kinetics are characterized the most. Most vat photopolymerization resins are acrylate-epoxy 
a

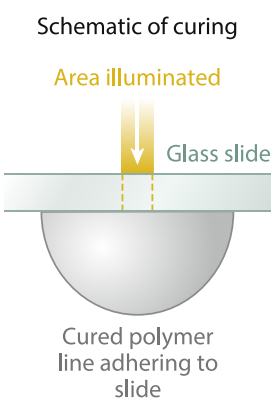

b $\begin{array}{lr}\text { Low RI contrast } & \text { Low Rl contrast } \\ E_{0}=54 \mathrm{~mJ} \mathrm{~cm}^{-2} & E_{0}=203 \mathrm{~mJ} \mathrm{~cm} \mathrm{~cm}^{-2}\end{array}$

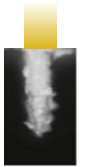

C

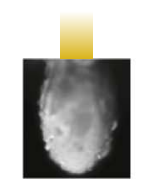

d

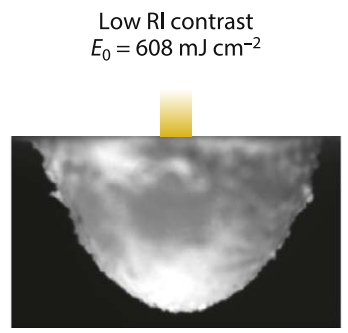

e

$\begin{array}{lc}\text { High RI contrast } \quad \text { High RI contrast } \\ E_{0}=203 \mathrm{~mJ} \mathrm{~cm}^{-2} & E_{0}=608 \mathrm{~mJ} \mathrm{~cm}^{-2}\end{array}$

Fig. 12. Cured line shape for different refractive index (RI) values, adopted from [7].

blends, so the cationic photopolymerization kinetics should be characterized as well [54]. The cure mechanism described hereafter is freeradical polymerization, while the cationic polymerization mechanism is similar, but more complex to model [56].

The cure mechanism in free-radical photopolymerization consists of a sequence of four steps: radical formation, initiation, propagation and termination $[8,54,55]$. Fig. 14 shows the cure mechanism in chemical equations. The first step radical formation is often categorized as part of the initiation step. In the radical formation step, the photoinitiator $I$ is dissociated with a rate constant $k_{d}$ upon absorption of photons having energy $h v$. In the initiation step, the primary radicals $R$. react with monomer $M$ to produce the chain initiating radical $P_{1}$. with an initiation rate constant $k_{i}$. During propagation, the chain initiating radical $P_{1} \cdot$ grows due to the successive addition of monomer. Each addition of a monomer molecule $M$ increases the polymeric radical $P_{n}$ by one monomer molecule to $P_{n+1}$. The rate constant for propagation is denoted by $k_{p}$. Finally, the polymer chains stop growing in the termination step with a rate constant $k_{t}$ due to combination or disproportionation.

The polymerization cure mechanism can be mechanistically modelled by setting up conservation laws for mass and energy, using the kinetic rate constants. More specifically, the species balance can be used to calculate the concentrations of components such as the monomer, photoinitiator and polymeric radical. A number of researchers have developed photopolymerization process models using this approach for vat photopolymerization specifically $[31,51,54,57,58]$ and for photopolymerization in general $[39,59]$. For example, Sun and Zhang [31] modelled the attenuation of light $I$, photoinitiation, propagation and termination respectively as follows:

$\frac{d I}{d z}=-\varepsilon^{\prime}[P I] I$

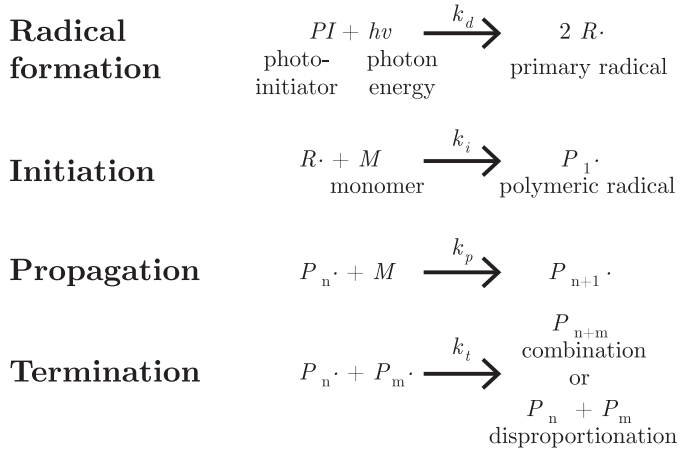

Fig. 14. Free-radical photopolymerization cure mechanism.

$\frac{d[P I]}{d t}=R_{i}=-\phi \varepsilon^{\prime}[P I] I$

$\frac{d[M]}{d t}=-R_{p}=-k_{p}[P \cdot][M]$

$\frac{d[P \cdot]}{d t}=R_{i}-R_{t}=\phi \varepsilon^{\prime}[P I] I-k_{t}[P \cdot]^{2}$

where $\phi$ is the quantum yield or efficiency, the terms between brackets represent concentrations, $R_{i}, R_{p}, R_{t}$ are the rates of initiation, propagation and termination respectively, and $k_{p}$ and $k_{t}$ are the rate constants for propagation and termination respectively. Similar differential equations are derived by, e.g., Tang [54].

\subsubsection{Degree of (monomer) conversion}

The extent of polymerization is quantified by the degree of monomer conversion, also known as degree of cure, cure level and fractional conversion. Bartolo describes the relationship between the

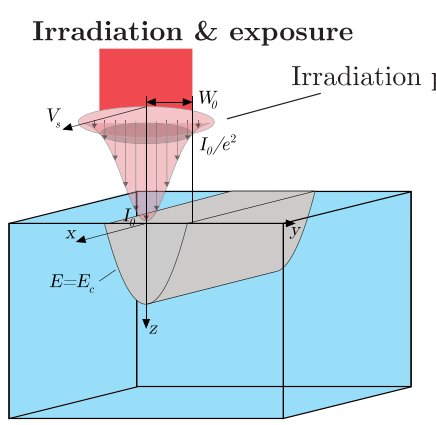

Exposure $\mathrm{E}(\mathrm{x}, \mathrm{y}, \mathrm{z})$
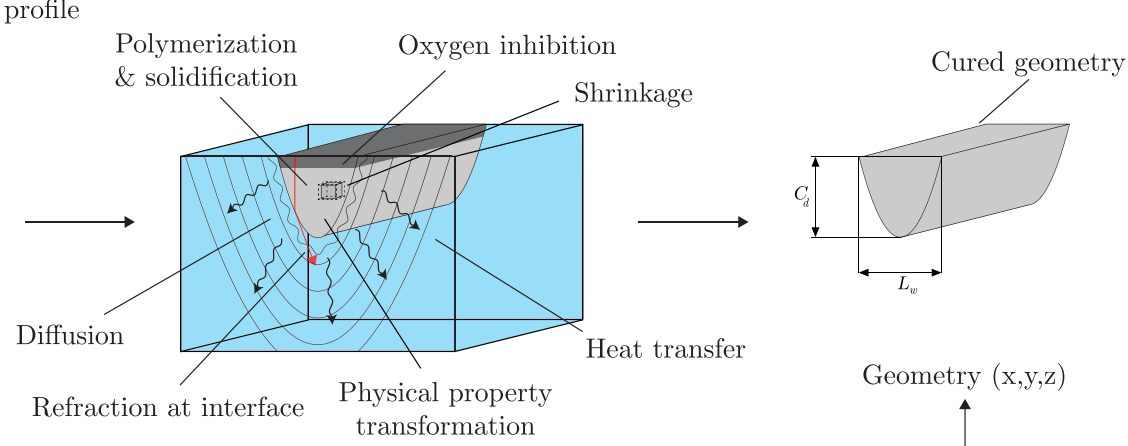

Geometry $(\mathrm{x}, \mathrm{y}, \mathrm{z})$

transformation

Exposure threshold modeling $E \geq E_{c}$

Fig. 13. Photopolymerization complexity illustrated by the many physical phenomena involved; image inspired by [54]. 


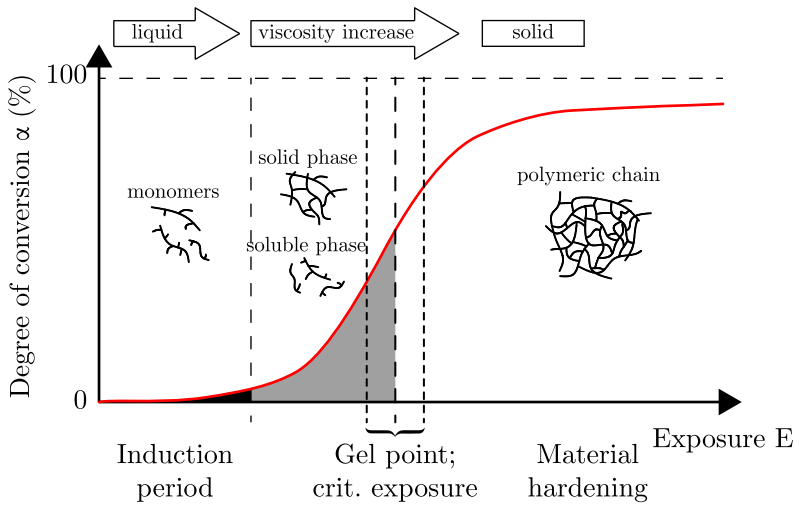

Fig. 15. Degree of conversion versus exposure; image adapted from [60].

glass temperature $T_{g}$ and degree of cure $\alpha$ [26]. A plot of the degree of conversion $\alpha$ as a function of exposure $E$ typically shows a sigmoidal curve $[7,26,48]$, as shown in Fig. 15.

After an induction period due to consumption of radicals by inhibitor such as oxygen present in the resin, the viscosity rapidly increases up to the gel point. The gel point is reached at the critical exposure $E_{c}$ and represents the point of abrupt transformation from viscous liquid to a gel. As the figure shows, the degree of conversion reaches an asymptote lower than $100 \%$. Rather than using an exposure threshold to model whether the gel point has been reached, Tang proposes a degree of cure threshold [54]. The main advantage of the latter is that the polymerization reaction and transient intensity effects are taken into account, rather than assuming that conversion simply increases with exposure independently of process dynamics.

Acrylate molecules have carbon-carbon double bonds that are converted into two single bonds, often referred to as double bond conversion in literature [61]. The degree of conversion can be calculated from the monomer concentration $[M]$ by simply taking the fraction of reacted monomer to the initial monomer concentration $\left[M_{0}\right]$ $[39,62]$ :

$\alpha=\frac{\left[M_{0}\right]-[M]}{\left[M_{0}\right]}$

Apart from the (semi-)mechanistic models based on species balances, phenomenological models were developed as well that calculate the degree of cure $\alpha$ directly $[26,60]$. The phenomenological models are given by the following equation:

$\frac{d \alpha}{d t}=k_{c}(T) f(\alpha)$

where $\frac{d \alpha}{d t}$ is the reaction rate, $f(\alpha)$ is a function of conversion and $k_{c}(T)$ the temperature-dependent rate constant. In its simplest form, the expression for $f(\alpha)$ is:

$f(\alpha)=(1-\alpha)^{n}$

where the constant $n$ corresponds to the reaction order. Moreover, the simplest expression for $k_{c}(T)$ is given by the Arrhenius law:
$k_{c}(T)=k_{0} e^{\frac{-E}{R T_{a b s}}}$

where $k_{0}$ is a pre-exponential factor, $E$ is the activation energy, $R$ the gas constant, and $T_{\mathrm{abs}}$ the absolute temperature. Thus the expression for the reaction rate becomes:

$\frac{d \alpha}{d t}=k_{0} e^{\frac{-E}{R T_{\mathrm{abs}}}} \cdot(1-\alpha)^{n}$

Variations of $f(\alpha)$ are used in literature to represent so-called autocalytic process, such as in the control-oriented process model by Yebi where $f(\alpha)=\alpha^{m}(1-\alpha)^{n}[63]$.

\subsubsection{Oxygen inhibition}

In free-radical polymerization, a typical degree of conversion plot over time shows an induction period that is accountable to oxygen inhibition [48], see Fig. 15. In inhibition of the photopolymerization reaction, an inhibitor species such as oxygen or another intentionally added inhibitor reacts with the growing chain rather than monomer and stops chain growth. The oxygen concentration dissolved in the resin depends on the system configuration; in free-surface systems the resin is irradiated at the resin surface and oxygen particularly inhibits at the surface where it is absorbed from the air [7]. In constrained-surface systems the resin is irradiated from the bottom and oxygen is replenished from the top as shown in Fig. 16. A method to remove oxygen from the resin is to purge the build chamber with nitrogen [64]. The effect of oxygen inhibition in ceramic suspensions was researched by several researchers $[65,66]$

To model oxygen inhibition, the cure mechanism in Fig. 14 is expanded with an inhibition reaction and the species balance for oxygen can be set up $[39,58]$. To this end, Altun extended the model by Tang [54] with oxygen inhibition [58]. Although oxygen inhibition is generally seen as a negative effect, it is an essential mechanism in constrained surface systems with continuous platform motion [21] to prevent adherence to the window.

\subsubsection{Heat transfer}

Since the photopolymerization reaction is an exothermic process, heat is generated during photopolymerization [8,54]. Physical phenomena related to heat transfer such as heat storage and conduction are usually modelled by the heat equation. The heat equation is derived from the conservation law for energy and is given by $[39,54,62]$ :

$\frac{\partial \rho c_{p} T}{\partial t}=k \nabla^{2} T+\Delta H_{p} R_{p}$

where $\rho$ is density, $c_{p}$ specific heat, $T$ temperature, and $k$ is thermal conductivity. Heat generation is modelled as the source term $\Delta H_{p} R_{p}$, which is the product of the heat of polymerization $\Delta H_{p}$ and rate of polymerization $R_{p}(16)$. Some works also include the heat by absorption of laser radiation $[39,63]$.

The choice of thermal boundary conditions can have a significant influence as exemplified by Yebi's control scheme [63] outlined in Section 5.1. Tang included natural heat convection at the free surface boundary [54]. Another important consideration is the change in (material) constants due to temperature changes. Although not explicitly evident from the formulas (14) to (17), the temperature
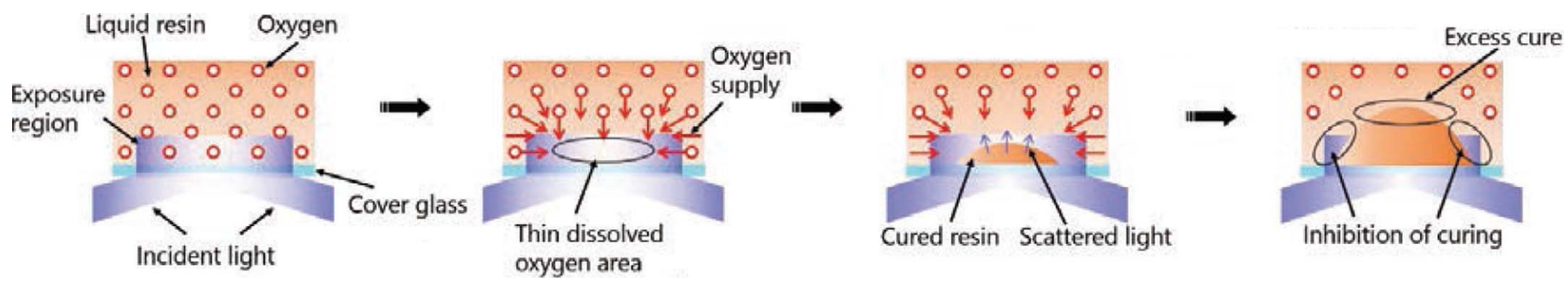

Fig. 16. Oxygen replenishment in a constrained-surface system; adopted from [64]. 
dependencies of the rate constants are often modelled using the Arrhenius law $[39,54]$ such as in $(21)$. Other material "constants" such as density $\rho$ are temperature dependent as well.

\subsubsection{Mass transfer}

Mass transfer occurs when mass moves from one location to another. Two types of mass transfer occur in vat photopolymerization, namely diffusion and convection of the chemical species. Diffusion of reactive species is modelled by adding diffusion constants to the species balance Eqs. (15)-(17). The equations then become [39,40,54]:

$\frac{d[P I]}{d t}=D_{P I} \nabla^{2}[P I]-\phi \varepsilon^{\prime}[P I] I$

$\frac{d[M]}{d t}=D_{M} \nabla^{2}[M]-k_{p}[P \cdot][M]$

$\frac{d[P \cdot]}{d t}=D_{P \cdot} \nabla^{2}[P \cdot]+\phi \varepsilon^{\prime}[P I] I-k_{t}[P \cdot]^{2}$

where $D_{P L}, D_{M}$, and $D_{P}$. are the diffusion constants for the photoinitiator, monomer and polymeric radicals respectively. Oxygen diffusion was similarly modelled by Altun [58]:

$\frac{\partial\left[O_{2}\right]}{\partial t}=D_{O} \nabla^{2}\left[O_{2}\right]-R_{\text {in }}$

where $R_{\text {in }}$ is the inhibition rate. Convection is the bulk motion of fluid and can be caused by shrinkage of the photopolymer; to model this effect it should be included in the mass balance equation [54]. Nakaga et al. studied the flow due to photopolymerization shrinkage [67].

\subsubsection{Shrinkage and distortion}

Resin shrinkage is the main reason for internal stresses and resulting part distortion such as warpage and curl and defects such as cracks, especially for nonuniform shrinkage [20]. In photopolymerization, shrinkage occurs due to two effects: thermal expansion and specific volumetric shrinkage. Thermal expansion occurs due to temperature fluctuations caused by exothermic heat generation. Specific volumetric shrinkage occurs due to carbon-carbon double bond conversion and the accompanying decrease in average distance between groups; consequently density increases [8]. An important phenomenon is that shrinkage lags exposure $[6,8]$. Flach and Chartoff modelled this lag between specific volumetric shrinkage and monomomer conversion for a line scan [68] as an extension to their process model [57]. Narahara et al. argue that the resin first shrinks due to volumetric shrinkage proportional to reaction extent, then expands thermally due to heat generation, and finally shrinks again due to cooling [69].

Several researchers developed models to quantify volumetric shrinkage and/or thermal expansion using finite element method (FEM) models [70-73]. Vatani et al. used classical laminate theory rather than FEM to predict part distortion [74]. These simulation models can be used to limit distortion through process planning optimization. Fig. 17 shows a comparison by Jiang between FEM distortion results and an actual built part [75].

Although most models are developed for pure photopolymer resins, a noteworthy FEM model is developed in the work of Wu [25] for stress, crack and delamination development in ceramic vat photopolymerization parts.

\subsubsection{Mechanical property variation}

Although fundamental to the applicability of functional parts, models of the final part's mechanical properties as a function of processing parameters are scarce. Already in the early days of vat photopolymerization, Jacobs developed an empirical model for the elastic modulus as a function of exposure [8]. The so-called photomodulus is defined as the Young's modulus for parts in the green state and serves as a measure for green part strength. The photomodulus as a function of

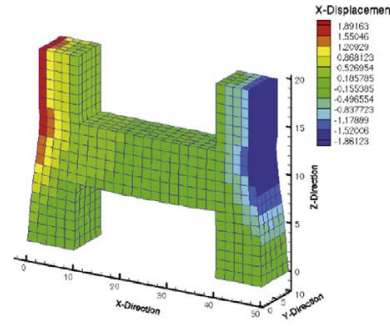

(a) FEM results

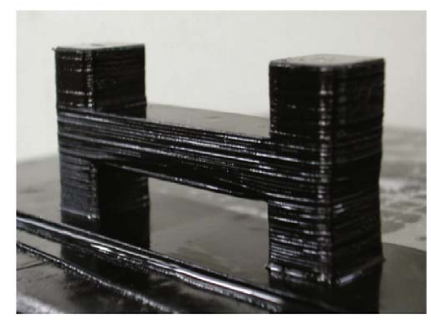

(b) actual built part
Fig. 17. Comparison of FEM distortion results with actual built part; adopted from [75].

exposure is described by the following equation [8]:

$\frac{Y}{Y_{\max }}=1-e^{-\beta\left(\frac{E}{E_{c}}-1\right)}, \beta=\frac{K_{p} E_{c}}{Y_{\max }}$

where $Y_{\max }$ is the maximum achievable modulus and $\beta$ is a resin constant that is a function of the photomodulus coefficient $K_{p}$. Huang and Jiang use a slightly modified version of the photomodulus model to include temperature dependency in their FEM model [73].

To the author's knowledge only two researchers have tried to model the mechanical resin characteristics during photopolymerization with a visco-elastic material model $[56,76]$. The obtained material model can be used as an input for FEM models [56] and can be linked to the reaction kinetics [77].

\subsection{Comparison of existing process models}

Models describing the phenomena outlined in the previous sections are compared in Table 1 . Note that this table is far from complete, since a plethora of other models is available that describe photopolymerization and related phenomena. An important model property is whether or not the model takes the presence of ceramic fillers into account and the irradiation method employed in the system. Concerning the curing mechanism, differences exist between the models that do not become evident from the table due to space limitations. Although all models that contain a cure kinetics model describe a free radical curing mechanism, they do not all explicitly model the four steps comprising the mechanism (radical formation, initiation, propagation, termination). Moreover, it becomes evident from the table that mask projection system models typically do not incorporate a cure kinetics model, probably due to the computational load associated with simulating many pixels at once.

\section{Process sensing and actuation}

Sensors and actuators are key components of any control system. Since there is a duality between sensing and actuation, they are often treated as pairs in control system analysis. Hence some sensor properties such as sensor placement must be considered in tandem with actuator properties such as actuator placement (colocation). In vat photopolymerization a similar duality exists as well for instance in the spatial dimensionality of the sensor and the actuator.

\subsection{Process actuation}

The goal of the photopolymerization step is to transform the material from the liquid to the solid phase by irradiating with the actuator, i.e., the light source. In the following section, alternative initiation methods for the polymerization reaction are surveyed. Subsequently, the methods to irradiate the layer are classified.

\subsubsection{Initiation method}

The way the polymerization reaction is initiated has a major 

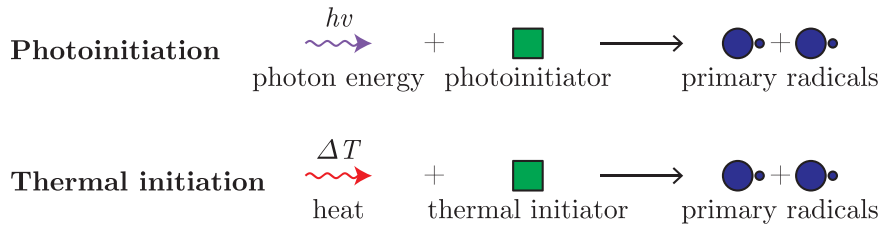

Fig. 18. Polymerization initiation mechanisms.

influence on the system architecture. Most polymerization reactions are thermal processes and are often initiated by supplying heat. In photopolymerization, the polymerization reaction is initiated by light exposure. Many other stimuli can be used to initiate the polymerization reaction as well, such as electron beams, X-rays, gamma rays, plasma, microwaves, pressure and addition of a catalyst $[84,85]$. Initiation by exposure to light forms a very elegant and powerful excitation approach [84] and is most commonly used in the additive manufacturing context. Fig. 18 shows the initiation mechanisms for photopolymerization and thermal polymerization.

Bartolo et al. developed a so-called stereo-thermal-lithography system that uses both UV radiation and IR radiation to initiate a polymerization reaction in a resin that contains both photoinitiators and thermal initiators [26,86]. More recently, an infrared stereolithography system was developed that uses solely IR radiation to thermally initiate a polymerization reaction [60]. It is important to note that photoinitiators can be thermally initiated as well at a high enough temperature, as demonstrated by Tang [54].

\subsubsection{Irradiation method}

The method by which the layers are irradiated by the light source, can be classified according to a classification scheme adapted from [6] and shown in Table 2. The irradiation methods can be distinguished by the geometry or spatial dimensionality kinteics of the light source on the part scale and the number of irradiation actuators that comprise this geometry. Furthermore, this geometry determines the amount of motion degrees of freedom (DOF) required to irradiate a complete layer. The total number of actuators and hence total number of input variables is the sum of the number of irradiation actuators and motion actuators.

Traditionally, a single laser point source scanned the resin surface to selectively irradiate the photopolymer, referred to as vector scanning [6]. To this end, the laser beam had to be positioned in two DOF in the horizontal $x y$-plane as shown in Table 2. Hence a total of three variables needed to be controlled and synchronized. To increase productivity, one or more lasers could be added to simultaneously irradiate multiple portions of the resin surface. Continuing to add more beams, one can use a 1D array or a line of $n$ points. If the individual points are touching, then the 1D array only has to be positioned in one DOF, e.g., along the $x$-axis as illustrated in Table 2. Extending this 1D array or line to a 2D array or area of $n \times m$ points, the array does not have to be positioned in the $x y$-plane at all. In these so-called mask projection systems, an entire surface can be selectively irradiated by, e.g., a Digital Micromirror Device (DMD) [6]. If the 2D array is positioned in one [87] or two [88] DOF in the $x y$-plane again, as in scanning mask projection, the build area can be increased or the resolution can be improved. Another mechatronic concept to address the inherent trade-off between build area and resolution, is to use a projector whose magnification can be controlled through vertical motion [89]. Many other combinations can be made within the presented classification scheme, such as, e.g., mask projection combined with vector scanning [90] or scanning mask projection using multiple projectors [34].

\subsection{Process sensing}

In-situ process measurements are a key enabler for the development of process control schemes, improvement of our understanding of the process, and improvement of process efficiency and part quality
$[14,15]$. The intended process control strategy determines the requirements such as speed and resolution for the sensing technology to be integrated into vat photopolymerization equipment.

The field of monitoring polymerization reactions in general is considerable, as exemplified by [91-93]. Not all the monitoring techniques are relevant for vat photopolymerization, since, e.g., in vat photopolymerization there are no forced flows of polymer as opposed to polymerization reactors. Other polymerization reactions that are more closely related to vat photopolymerization are photolithography, coating and dental composite material reactions [94]. Scrutinizing literature on process sensing and control of these related technologies may prove worthwhile [95].

The approach taken here is to analyze (photo-) polymerization monitoring and characterization techniques and attempting to extract the measuring principles for the development of in-line sensors to be integrated into vat photopolymerization equipment. Even offline, polymer characterization is a complex and challenging field [91]. So although the majority of techniques reviewed here were originally developed to study the photopolymerization process rather than to control the process, some techniques might be applicable as in-line metrology.

The choice of process variable to be measured by the sensing technology, i.e., the measurand, naturally follows from the intended process control scheme. The degree of (monomer) conversion is often considered a highly useful measurand for monitoring and control $[63,93]$ and hence is the focus of this section. Many different sensing techniques exist to measure the degree of conversion, each with their own advantages and disadvantages. The measuring principles governing these techniques are explained in the following sections, followed by a comparison.

\subsubsection{Spectroscopy}

Spectroscopy is the field of study concerned with the interaction of electromagnetic radiation and matter [96]. Two spectroscopic measurement techniques have been widely used to monitor the change in concentration of chemical species and consequently the degree of conversion during the photopolymerization reaction, namely infrared (IR) spectroscopy [97] and Raman spectroscopy [98]. Both techniques rely on measuring the vibrational energy of molecules, which consist of atoms bound together by chemical bonds. Other spectroscopic techniques for monitoring photopolymerization reactions include fluorescence spectroscopy [49] and surface plasmon resonance spectroscopy [99]. IR spectroscopy has been used for kinetic analysis of ceramic slurries $[61,100,101]$.

Molecules can be considered as consisting of coupled harmonic oscillators where the atoms are point masses and the bonds are springs [102]. Two of these oscillators represent the carbon-carbon double bond, one in a stretching mode and the other in a twisting mode. The vibrational energy of each functional group represented by harmonic oscillators is a function of the concentration of said group and thus spectroscopy can be used to monitor the photopolymerization reaction. As monomer is consumed, double bond conversion takes place, which is perceptible in the spectrum as a decrease of corresponding peaks. The degree of conversion $\alpha$ can be calculated at any time by taking the ratio of the current peak height or area $A$ to the initial peak height or area $A_{0}$.

The measuring principle governing IR spectroscopy is the absorption of light in a medium, which can be quantified by the Beer-Lambert law [38]. The Beer-Lambert law states that the absorbance $A$ is directly proportional to the wavelength $\lambda$ and sample concentration $[c]$. As monomer is consumed during the reaction, the monomer concentration decreases and consequently the absorbance decreases. Absorbance can be simply obtained by irradiating the medium with a known intensity and measuring the outgoing intensity, see Fig. 19. Two common methods to measure absorbance are the transmittance (TR) and attenuated total reflection (ATR) methods. In the transmittance method shown in the left of Fig. 19, the absorbance is measured by placing the IR source and detector in line, such as in [103]. In the ATR method, a crystal with high index of 


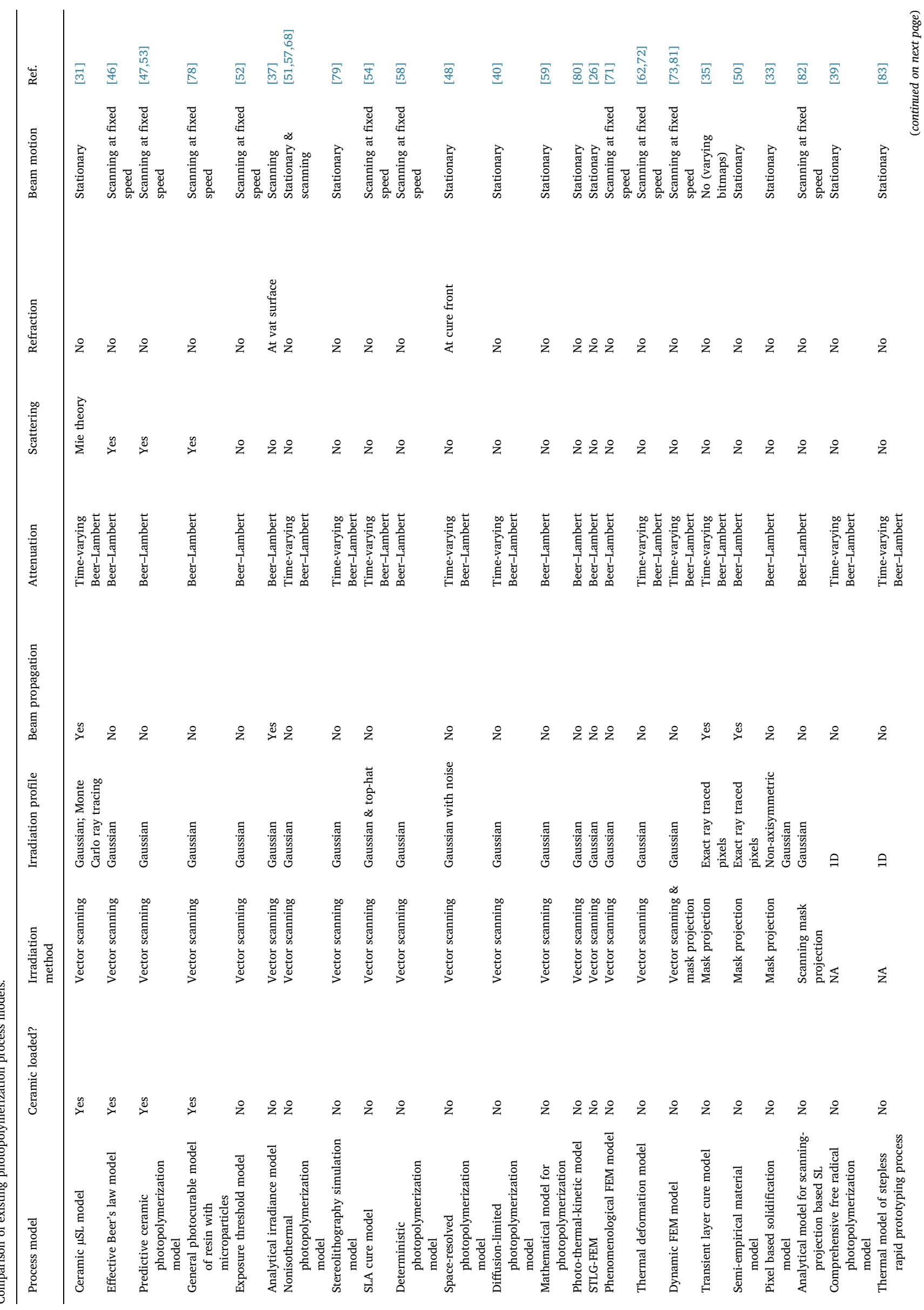




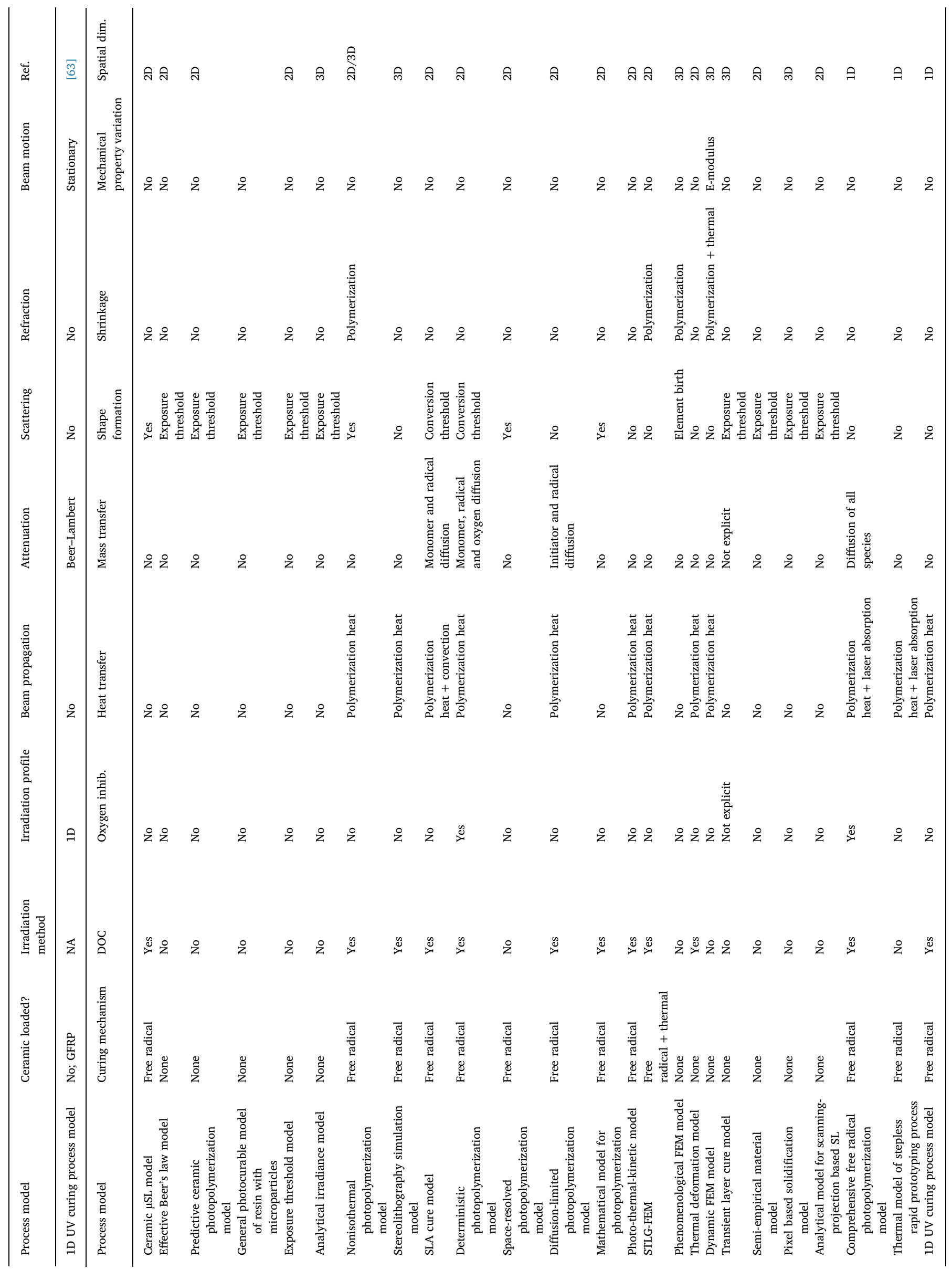


Table 2

Irradiation methods classification scheme, adapted from [6].

\begin{tabular}{|c|c|c|c|c|c|}
\hline \multirow{2}{*}{$\begin{array}{l}\text { Irradiation } \\
\text { method }\end{array}$} & \multicolumn{3}{|c|}{ Vector scanning } & \multirow{2}{*}{$\begin{array}{l}\text { Mask } \\
\text { projection }\end{array}$} & \multirow{2}{*}{$\begin{array}{l}\begin{array}{l}\text { Scanning } \\
\text { mask } \\
\text { projection }\end{array} \\
\begin{array}{l}n \times m \\
\text { point array }\end{array}\end{array}$} \\
\hline & 1 & 2 & $n$-point array & & \\
\hline $\begin{array}{l}\text { Geometry } \\
\text { Schematic }\end{array}$ & Point & Points & $\begin{array}{l}\text { Line } \\
\qquad \leftrightarrow x\end{array}$ & Area & Area \\
\hline $\begin{array}{c}\text { \# Motion } \\
\text { DOF }\end{array}$ & 2 & $2 \times 2$ & 1 & 0 & 2 \\
\hline
\end{tabular}

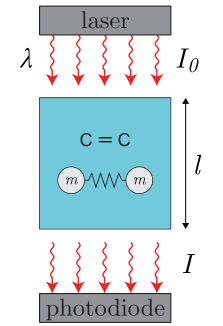

Transmission mode

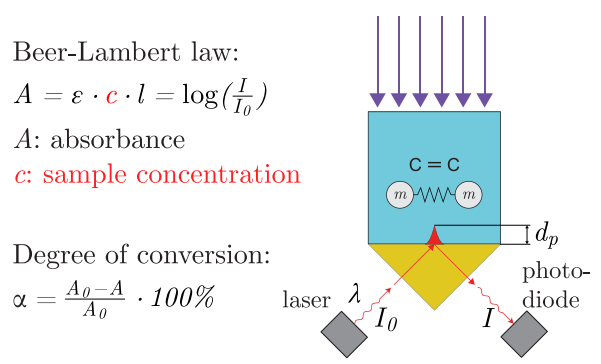

ATR mode
Fig. 19. IR spectroscopy measuring principle.

refraction is used as is shown in right of Fig. 19. As the IR beam reaches the boundary, total internal reflection occurs; a small amount of light penetrates the photopolymer medium in the form of an evanescent wave with penetration depth $d_{p}$ and is partially absorbed before being measured by the photodiode. Both the TR and ATR methods can be embodied in a fiber optic probe for remote sensing [91].

The goal of IR spectroscopy is to measure the absorption for a range of wavelengths, which can be done in two ways. The first way is to physically split up the radiation in its constituent wavelengths in what is called dispersive spectroscopy and to measure the absorption for each individual wavelength monochromatically [102]. A second way is to radiate the sample with multiple wavelengths simultaneously in what is called Fourier Transform IR spectroscopy (FTIR). In FTIR, a Michelson interferometer with a stationary and moving mirror is used as a multiplexer to select a set of wavelengths and the resulting time domain interferogram is Fourier transformed to the frequency domain. Note that Fig. 19 does not show the interferometer, which can have considerable dimensions with respect to the sample.

\subsubsection{Interferometry}

Laser interferometric techniques that rely on refractive index changes upon polymerization have been employed by several researchers to monitor the photopolymerization process, using both Michelson [65,104-108] and Mach-Zehnder [109,110] configurations. The goals of these systems range from monitoring shrinkage-induced deformations $[104,108]$ to monitoring the degree of cure [107]. To the author's knowledge, the only work attempting to use interferometry for ceramic vat photopolymerization is [65]. However, the experiments herein were not performed on ceramic suspensions, but on unfilled resins.

The measuring principle is based on detecting differences in optical path lengths (OPL) upon photopolymerization as illustrated in Fig. 20. The optical path length is the product of the refractive index $n$ and the geometric length $d$. During photopolymerization, the refractive index of the photopolymer will typically increase and the geometric length or thickness will typically decrease due to shrinkage. Consequently the total optical path length difference will cause a periodic modulation of the intensity of the reflected laser beam by interference of light as indicated in Fig. 20.

Jariwala developed an in-situ interferometric cure monitoring (ICM) system based on Mach-Zehnder interferometry for measuring part dimensions in the setup described in Section 5.2 and shown in Fig. 26 [50]. Zhao improved the ICM system by moving from an implicit model relating measured phase angle to cured height empirically to a parameter estimation based method using an elaborated optics model [111]. The ICM system potentially enables real-time, full-field part shape measurements for the layerless process [112].

\subsubsection{Calorimetry}

Calorimetry is the science of measuring heat transfer associated with chemical reactions or physical changes and is a well-established method for the characterization of polymerization reaction kinetics [91]. Photocalorimetry is simply calorimetry for the study of light-induced processes, such as photopolymerization [113]. As described in Section 3, in free radical polymerization reactions, carbon-carbon double bonds $(\mathrm{C}=\mathrm{C})$ are converted into two single bonds. The amount of heat $Q_{r}$ generated during this conversion can be calculated from the difference between the bond energy of the double bond and the two single bonds [113]. Hence, a simple expression for the degree of cure $\alpha$ can be derived for isothermal processes [26,54,113]:

$\alpha=\frac{Q_{r}}{Q_{\text {tot }}}$

where $Q_{t o t}$ is the known total reaction heat when all monomers are converted. Thus, the measuring principle governing photocalorimetry for following cure reactions is based on the measurement of generated exothermic heat.

The most widely used method to measure exothermic heat is Differential Scanning Calorimetry (DSC) [113]. "Differential" means that the change of the difference in heat flow rate to the sample and the reference is measured, while "scanning" means that they are subjected to a controlled temperature program [114]. Many researchers have used photo-DSC for kinetic analysis of vat photopolymerization reactions for pure resins $[8,54]$ and ceramic slurries [115]. Fig. 21 shows the measuring principle in power compensation DSC.

The measuring principle in heat flux DSC is to measure the difference in temperature $\Delta T$ between the sample and reference, whereas in power compensation DSC the measuring principle is to measure the required compensation heat $\Delta Q$, while the temperature is kept (nearly) constant by a control system [114]. Although the extraction of the power compensation DSC measuring principle for use as an in-situ sensor for vat photopolymerization seems non-trivial, the measurement of released reaction heat by means of temperature measurement (i.e., thermometry) seems more likely.

\subsubsection{Thermometry}

Photopolymerization is an exothermic process and therefore the usage of temperature measurements, i.e., thermometry, to monitor the cure process seems a viable option. Several researchers have attempted to monitor the cure reaction using a single-point optical pyrometer [116] or an arrayed pyrometer in the form of an IR thermal imaging camera $[63,83,117]$. The measuring principle of pyrometers is based on the detection of infrared radiation from the object to be measured [118]. The usage of thermocouple arrays is also reported in literature [75].

\subsubsection{Dielectrometry}

Dielectric analysis is an established method [119] to monitor thermoset cure reactions and has been successfully applied to photoinitiated cure reactions [120-122]. The dielectric measuring principle is equivalent to that of an impedance measurement [123] and works as follows. A sinusoidal voltage is applied across two electrodes that are in 


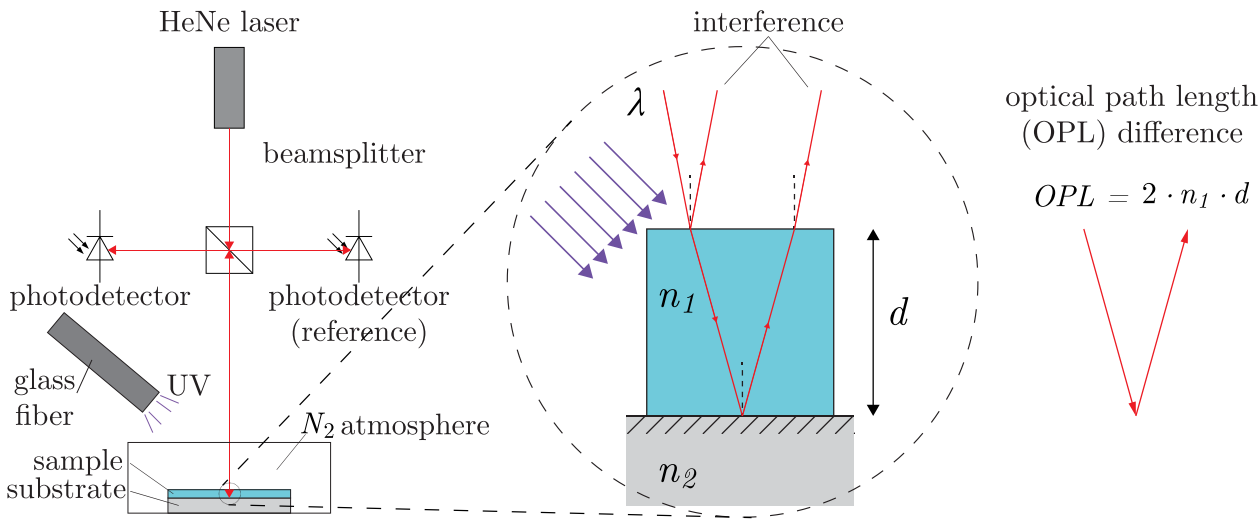

Fig. 20. Interferometry measuring principle, setup adopted from [105].

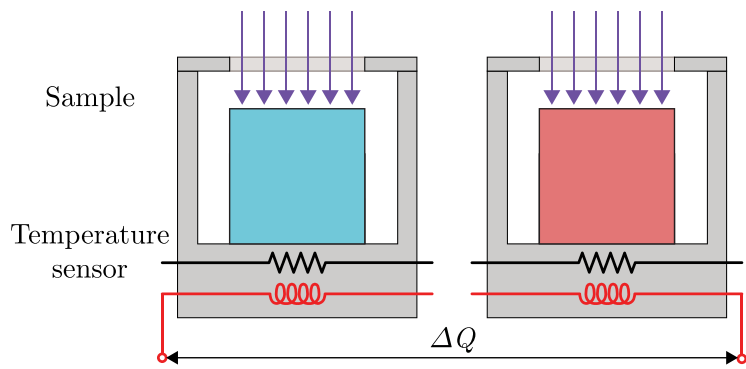

Reference

Fig. 21. Differential scanning calorimetry (DSC) measuring principle.

Without external field With external field
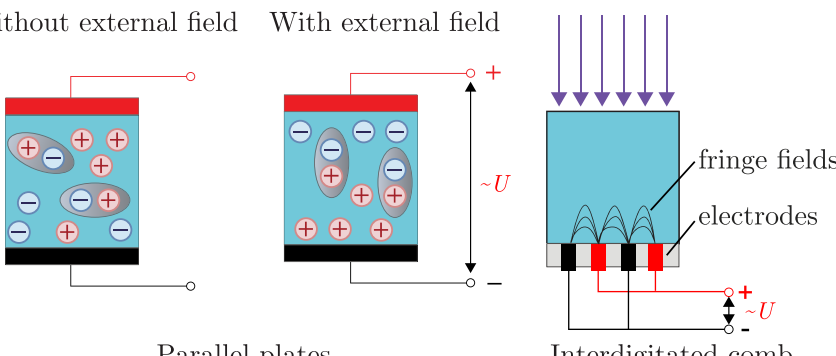

Parallel plates

Interdigitated comb

Fig. 22. Dielectrometry measuring principle, adopted from [123].

contact with the photopolymer sample as shown in Fig. 22. Dipoles will try to orient with the electric field whilst charged ions will move towards the electrode of opposite charge [120]. Two fundamental dielectric properties can be derived from a measurement of the changes in amplitude and the phase shift of the current response, namely the dielectric constant or permittivity $\varepsilon^{\prime}$ and the dielectric loss factor $\varepsilon^{\prime \prime}$. Since a strong correlation exists between the ionic mobility component of the loss factor, which is described by the ion viscosity, and the mechanical viscosity [120], dielectric analysis can be used as a cure monitoring technique.

A typical implantable sensor geometry consisting of two interdigitated comb electrodes rather than parallel plates is also shown in Fig. Fig. 22. These sensors can be used to irradiate the photopolymer sample on one side and subject the sample to an electric field for measurement on the other as shown in Fig. 22. The penetration depth of the fringe field into the sample is controlled by the electrode line width and spacing. Hence spatial variations in the vertical direction can be measured using different penetration depths [124]. The effects of ceramic fillers on the ion viscosity are discussed in [122].

\subsubsection{Rheometry}

Rheological methods to measure the change in mechanical properties upon curing can be used to monitor photoinduced curing. To this end, traditional rheometers are typically augmented with a light source

$[125,126]$. The combination of rheological techniques with spectroscopic techniques allows for the simultaneous measurement of both cure kinetics and mechanical properties [125,127]. Due to the fast curing of photopolymers, the data acquisition rate for typical rheometers is too low, i.e., in the order of $1[\mathrm{~Hz}]$. Hence, Schmidt incorporated high-performance data acquisition on a photorheometer, running at 1000 [Hz] [107]. Abstracting such rheological measurement techniques and incorporating them in a vat photopolymerization machine for in-situ cure monitoring seems non-trivial. Rheological techniques using particle tracking velocimetry seem more feasible.

Slopek developed such an in-situ monitoring system for free-radical photopolymerization based on particle tracking microrheology [125]. The measuring principle is based on the tracking of the Brownian motion of micron-sized fluorescent silica particles by video microscopy. The goal of the monitoring system was to monitor the liquid-to-gel transition in real-time and to enable the monitoring of changes in mechanical properties during photopolymerization [125]. Fig. 23 shows the experimental setup, which incorporated focus knobs to vertically shift the focal plane to enable measurements throughout the sample depth of $120[\mu \mathrm{m}]$.

\subsubsection{Wave propagation techniques}

Wave propagation techniques have been primarily used for cure monitoring of thermosetting polymers [129], but have also been applied in photopolymerization [130]. The measuring principle is based on the change of wave propagation characteristics due to the change in mechanical properties upon polymerization. For example, in ultrasonic cure monitoring an acoustic wave is transmitted by a transducer through a polymer sample and received by a second transducer [131]. Fig. 24 schematically shows two acoustic cure monitoring configurations: a contactful configuration and a contactless or air-coupled configuration [132]. The wave propagation velocity, also known as speed of sound, can be obtained by measuring the "time of flight" and is directly related to the resin storage modulus $L^{\prime}$ and density $\rho$ [132]. During polymerization the wave propagation velocity typically increases. The longitudinal modulus $L$, consisting of a storage $L^{\prime}$ and loss

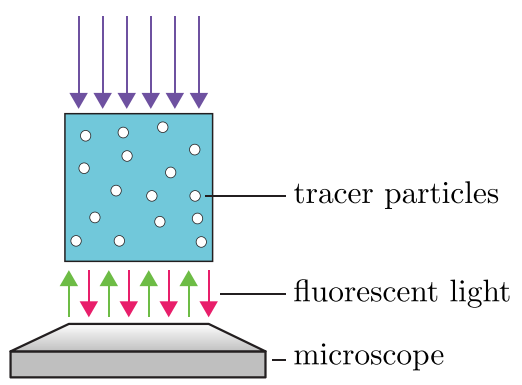

Fig. 23. Microrheology experimental setup, adapted from [125,128]. 


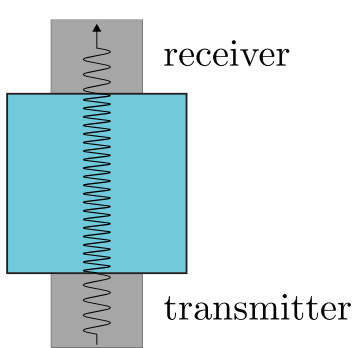

contactful
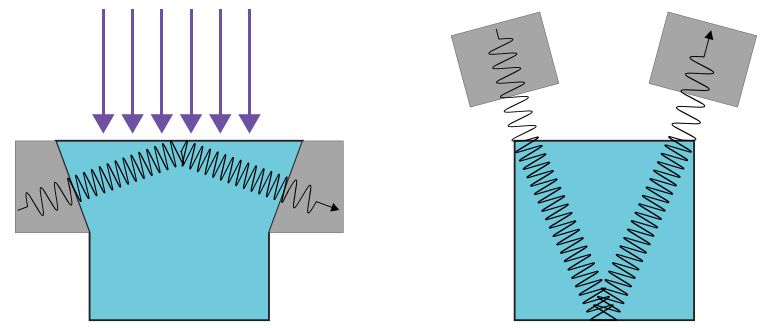

air-coupled

Fig. 24. Acoustic cure monitoring measuring principle.

$L^{\prime \prime}$ component, can be calculated from the wave propagation velocity and these can be subsequently correlated to other elastic moduli and the degree of cure $\alpha$ [132]. Laser ultrasonic sources and sensors have been used as alternative transducers for non-contact ultrasonic measurements [133].

\subsubsection{Comparison of existing sensing technologies}

Table 3 compares the sensing methods for measuring the degree of conversion, whose measuring principles are described in the preceding sections. Most sensing methods do not measure conversion directly, but derive it from the actual measurand. The spatial dimensionality of the measured conversion differs among the various sensing methods. Most sensing methods do not measure spatial variations in the $x y$-plane or along the $z$-axis, but average over the volume and hence are called point-based methods. Some methods do measure spatial variations in the $x y$-plane by using an arrayed sensor such as a CCD to capture a full field or area $[50,99,117,125]$. The only sensing methods reported to be able to measure spatial variations along the $z$-axis are particle tracking microrheology [125] and dielectrometry [124]. Sensor properties related to the spatial dimensionality not listed in the table are the spatial measurement range and resolution. Another relevant sensor property is whether the measurement is contactful or contactless.

For implementability in vat photopolymerization machines, the space the sensor occupies and the ability to measure and actuate from the same side are relevant properties. Figs. 19-24 illustrate that most of the surveyed sensing methods are only capable to measure a single photopolymer layer from one side, while irradiating it from the other. Note that although interferometric sensing methods irradiate and measure from the same side, they do require a reflective background, which complicates their suitability as a multi-layer sensor.

Both in IR spectroscopy $[61,100,101]$ and in calorimetry [115], the effect of ceramic particles on the functioning of the sensor is insignificant. In dielectrometry [122] and (parallel plate) rheometry [65], the ceramic filler has a significant influence on the measured quantities, but does not impair the functioning of the sensor. In interferometry, light scattering is expected to have a significant influence on the functioning of the sensor. The effect of ceramic fillers on thermometers and wave propagation techniques is not reported.

\section{Process control}

Consistent, repeatable part quality is a key requirement for enabling the application of AM in series production. Variability in part quality can affect both product yield and productivity [7], i.e., productivity is determined both by cycle time and product yield. Hence, the objective of a manufacturing process controller is to minimize production variations for a target geometry and properties despite the presence of material and process uncertainties [10]. Rejecting these disturbances is the purpose of feedback control.

Although not the focus of this paper, setpoint generation can be considered a control task as well. In vat photopolymerization, the desired process trajectories are determined by the build style employed. The build style is typically a sequence of scan patterns in vector scanning systems and a sequence of bitmaps in mask projection systems. Many research has been conducted on build styles in non-ceramic resins $[6,8,20,34,35,134]$. The build styles appropriate for pure non-ceramic resins may need to be modified for ceramic slurries [23]. Some research has been conducted on build styles specifically for ceramic vat photopolymerization [24,135-137].

Yet another type of control loop that is not directly the focus of this paper, is to monitor and control the input variables to ensure that the equipment is actually delivering the commanded inputs [9]. In vat photopolymerization this implies monitoring the irradiance distribution of the light source. Several researchers have employed a camera such as a CCD or CMOS to monitor the irradiance distribution on the vat surface [64,138-141].

Table 3

Comparison of existing sensing technologies.

\begin{tabular}{|c|c|c|c|c|c|c|c|c|}
\hline $\begin{array}{l}\text { Sensing } \\
\text { method }\end{array}$ & Measurand & $\begin{array}{l}\text { Derived } \\
\text { property }\end{array}$ & $\begin{array}{l}\text { Measuring } \\
\text { principle }\end{array}$ & $\begin{array}{l}\text { Spatial } \\
\text { dimensionality }\end{array}$ & $\begin{array}{l}\text { Sampling } \\
\text { rate }[\mathrm{Hz}]\end{array}$ & Contact & $\begin{array}{l}\text { Ceramic filler } \\
\text { influence }\end{array}$ & Ref. \\
\hline Spectroscopy & $\begin{array}{l}\text { Aborption } \\
\text { spectrum }\end{array}$ & Conversion & $\begin{array}{l}\text { Vibrational energy of } \\
\text { molecule measurement }\end{array}$ & Point & 1 & Contactful & Insignificant & {$[97,98,102]$} \\
\hline Interferometry & $\begin{array}{l}\text { Optical path length } \\
\text { change }\end{array}$ & $\begin{array}{l}\text { RI change, shrinkage, } \\
\text { conversion }\end{array}$ & $\begin{array}{l}\text { Optical path length } \\
\text { difference measurement }\end{array}$ & Point, area & 200 & Contactless & Significant & {$[65,104-110]$} \\
\hline Calorimetry & Reaction heat & Conversion & $\begin{array}{l}\text { Generated heat } \\
\text { measurement }\end{array}$ & Point & 1 & Contactful & Insignificant & {$[113,114]$} \\
\hline Thermometry & Temperature & Conversion & $\begin{array}{l}\text { Thermal radiation } \\
\text { measurement }\end{array}$ & Point, area & 100 & Contactless/-ful & Not reported & [116-118] \\
\hline Dielectrometry & $\begin{array}{l}\text { Permittivity, loss } \\
\text { factor }\end{array}$ & $\begin{array}{l}\text { Ion viscosity, } \\
\text { conversion }\end{array}$ & Impedance measurement & Point & 200 & Contactful & Insignificant & [119-124] \\
\hline Rheometry & Viscosity & Gel point & $\begin{array}{l}\text { Particle tracking/ shear } \\
\text { flow torque }\end{array}$ & Point, area & 1000 & Contactless/-ful & Insignificant & {$[107,125-128]$} \\
\hline $\begin{array}{l}\text { Wave propagation } \\
\text { techniques }\end{array}$ & Speed of sound & $\begin{array}{l}\text { Longitudinal } \\
\text { modulus, conversion }\end{array}$ & $\begin{array}{l}\text { Time of flight } \\
\text { measurement }\end{array}$ & Point & 100 & Contactless/-ful & Not reported & [129-133] \\
\hline
\end{tabular}


At the time of writing, only three control solutions are reported in literature in which feedback control is applied to a vat photopolymerization cure process or similar. In the first case the control objective is to minimize cure level deviations with layer depth [63] and in the second case the objective is to control the cure height in a bottom-up vat photopolymerization system [142]. In the third case a controller is developed for a system with continuous platform motion [143]. These three control schemes are outlined in the following sections.

\subsection{Model-based control of a UV curing process}

Yebi developed several model-based process control schemes for a layer-by-layer UV curing process of thick resin-infused glass fiber composites [63]. This AM technique is highly similar to vat photopolymerization in the vertical direction, but energy is not patterned in the horizontal plane. A first control scheme for feedback control in curing a single layer has been developed that partially compensates for UV attenuation across layer depth. Since the cure rate is proportional to temperature, the idea is to increase the cure rate by retaining heat at the bottom of the layer where the irradiation intensity is the lowest $[39,63]$. Fig. 25 illustrates this compensation strategy and the feedback control scheme that incorporates a temperature trajectory tracking controller, a temperature distribution observer and a cure level distribution observer.

A second control scheme for multi-layer parts is also proposed by Yebi termed stepped-concurrent curing (SCC) in which new layers are added before previous ones are completely cured. Robust process control is achieved through an offline optimization of the inter-layer hold times and UV intensity in the presence of parameter uncertainty by minimizing the final cure level deviation. Finally, in a cascaded control scheme, a high level loop generates a reference surface temperature and optimizes the inter-layer hold times, and a low level loop tracks the generated surface temperature trajectory using feedforward and feedback components.

\subsection{Evolutionary cycle to cycle control}

Zhao et al. developed a process control scheme for a layerless micro vat photopolymerization process in which parts are fabricated on a stationary substrate $[142,144]$. The cured height of the microparts that are "grown" bottom-up, is controlled in a scheme termed Evolutionary Cycle-to-Cycle (EC2C) control. EC2C is essentially an online parameter estimation algorithm that does not require accurate or detailed models [142]. The controller predicts the remaining exposure dose, calculates the remaining exposure time of the bitmap and switches to the next bitmap if necessary [144]. The actual cured height is measured by an interferometer, filtered using a Kalman filter, and used in the calculation of the remaining exposure time. Fig. 26 shows the cure height control scheme and the used setup.

\subsection{D Error based iterative learning control}

Türeyen et al. developed a so-called 3D error based learning controller for a vat photopolymerization system with continuous platform movement [143]. In this control scheme, the actual light intensity on the resin surface is obtained by taking an image of the resin surface with a CCD camera and calibrating to the light intensity obtained from a power meter. The obtained actual light intensity is used as an input to a build simulation using a simple exposure threshold model. The reference image is also used in the build simulation to obtain a reference geometry. The algorithm then calculates the total error between the actual simulated geometry and the reference simulated geometry for each layer by adding the error values of all pixels in a layer. Based on the error, the (continuous) platform speed is then increased when overexposed or decreased when underexposed. After simulating all layers, the build simulation is repeated for several iterations. In essence the algorithm developed by Türeyen et al. merely changes process parameters (platform speed for each layer) through the iterative simulation of the build process and hence the name iterative learning controller is probably not the most appropriate one.

\subsection{Comparison of existing control schemes}

The control schemes described in the previous sections are compared in Table 4. Relevant control scheme properties include the control objective, controlled variables, and controller type. Other relevant properties are the type of system that is controlled, the amount of layers the controller addresses, the spatial dimensionality of the controlled variables, and the type of sensor used.

\section{Discussion on control strategy feasibility}

To examine the feasibility of potential control strategies, the following sections consider the first steps in the process of designing a control system.

\subsection{Control objectives}

The first step in control system design is to study the system and the control objectives [145]. Typical control objectives include disturbance rejection and command tracking, which can be expressed by bounds on the error [145]. The existing photopolymerization control schemes in Table 4 essentially show two types of control objectives: (1) minimizing spatial variations in degree of conversion, and (2) minimizing dimensional errors. Yebi argues that degree of conversion and thermal

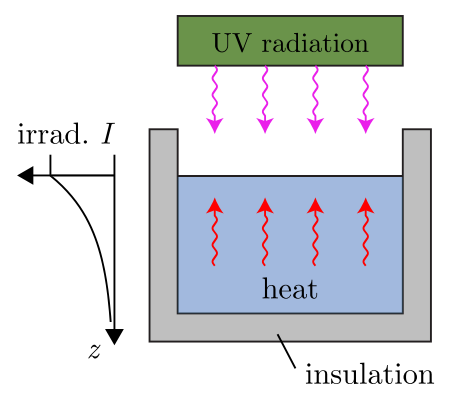

(a) compensation strategy for UV attenuation

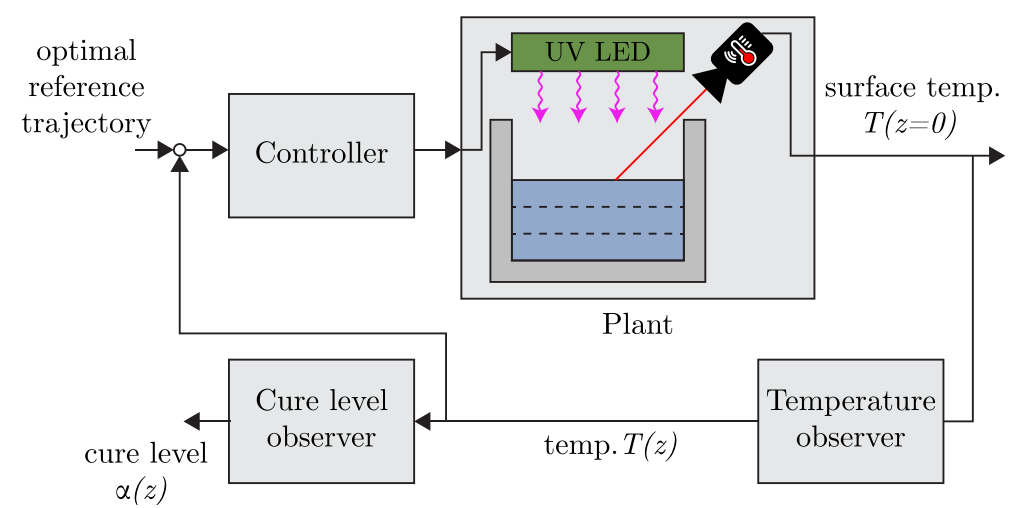

(b) feedback control scheme

Fig. 25. Model-based control strategies for a UV curing process, based on [63]. 
gradients compromise the quality and mechanical performance of the end product and hence accordingly formulates a control objective [63]. The degree of conversion is often measured in the characterization of polymerization reactions and hence seems a straightforward variable to control $[91,93]$.

A different control objective could be to minimize shrinkage strains. This objective is central to several build styles developed for vector scanning systems, which have led to significant accuracy improvements for pure resins $[6,8,20]$. Mitteramskogler et al. [24] showed that for ceramic-filled resins, minimizing shrinkage strains from photopolymerization can prevent crack formation after debinding. Yet another control objective could be to minimize the fraction of uncured resin, which was also a key aspect in the build styles for vector scanning systems $[6,8,20]$. Bae and Halloran [23] hypothesize that uncured resin in ceramic green parts could be the cause for cracking due to thermally initiated polymerization during debinding. Interestingly, the gaps in the "STAR-WEAVE" scanning pattern [8] intentionally introduced for minimizing shrinkage strains, contradict the objective of minimizing the fraction of uncured resin.

\subsection{Modelling}

The second step in control system design is to model the system. Over the years, a significant amount of models have been developed to describe the physical phenomena outlined in Section 3. Table 1, however, shows that the vast majority of the models describe the photopolymerization of pure resins, rather than of ceramic slurries. Moreover, at the time of writing only one photopolymerization process model has been developed intended for control [63]. Low-order, control-oriented models that only capture relevant phenomena should be developed for implementation reasons.

The cure mechanism represents the dynamics of the process to be controlled. Both the mechanistic models consisting of a set of coupled differential equations and the phenomenological models consisting of a single equation, show that the photopolymerization process has nonlinear dynamics. Moreover, the process is irreversible as the degree of conversion cannot decrease. The attenuation of light with depth introduces a significant spatial distribution of the input. This classification implies that control methods from classical control theory in the frequency domain cannot be applied, since they are typically based on sinusoidal steady-state responses.

The currently available process models essentially serve two purposes for control system design. On the one hand, they provide the control engineer with a description of the input-output behaviour of the system for use in model based control system design. On the other hand, they reveal the disturbances acting on the system, which enables the determination of the impact of rejecting these disturbances on the final product.

In modelling for control applications, an analysis of the time scales at which the physical phenomena manifest themselves is relevant. It should be noted from the outset that the photopolymerization process in vector scanning systems takes place in different time scales than in mask projection systems. Jacobs outlined the time scales relevant for vector scanning systems $[6,8]$ :

- $t_{t}=\mathcal{O}\left(10^{-12}[\mathrm{~s}]\right):$ photon layer transit time

- $t_{k}=\mathscr{O}\left(10^{-6}[\mathrm{~s}]\right): 1 / e$ kinetic reaction time constant

- $t_{e}=\mathcal{O}\left(10^{-5}-10^{-3}[\mathrm{~s}]\right)$ : characteristic exposure time

- $t_{s, o}=\mathscr{O}\left(10^{-1}-10^{0}[\mathrm{~s}]\right)$ : measurable shrinkage onset

- $t_{s, c}=\mathcal{O}\left(10^{0}-10^{1}[\mathrm{~s}]\right)$ : shrinkage completion

- $t_{d}=\mathcal{O}\left(10^{1}-10^{2}[\mathrm{~s}]\right)$ : total layer drawing time

The characteristic exposure time $t_{e}$, i.e., the time for the laser beam to traverse the "zone of influence" that receives $99.99 \%$ of its total exposure, is larger than the characteristic time for the kinetic reaction $t_{k}$ [8]. The implication for control is that there is a window of opportunity 


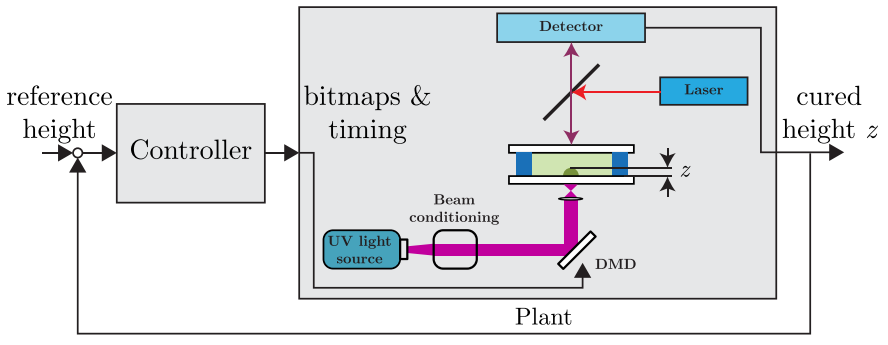

Fig. 26. Cure height control scheme, based on [142].

in which the photopolymerization process has already been initiated whilst still being irradiated. Hence, the laser power can potentially be adjusted according to a feedback control law if sensing, computation and actuation is fast enough. Minimizing shrinkage strains would require a model that - despite the evident time scale separation between polymerization and shrinkage - is capable of accurately predicting shrinkage.

The time scale analysis in [8] did not include the time scales related to oxygen inhibition, heat transfer and diffusion of species. Since these phenomena influence the reaction rates, their respective time scales are of interest as well.

In stationary mask projection systems, the characteristic exposure time $t_{e}$ and total layer drawing time $t_{d}$ are equal. If mask projection systems would use the same irradiance values to irradiate the entire surface as vector scanning do to irradiate only a small region, the required total power of the light source would be many orders higher. Hence, it can be easily seen that the irradiance values are orders lower in mask projection systems, i.e., milliwatts $[33,146]$ rather than watts per centimetre squared [8]. To reach the same exposure level, the characteristic exposure times $t_{e}$ are in the order of seconds to tens of seconds in mask projection systems. Consequently, the polymerization reaction in mask projection systems is generally much slower than in vector scanning systems and thus the $1 / e$ kinetic time constant $t_{k}$ is higher. So the $1 / e$ kinetic time constant described by Jacobs $[8] \mathcal{O}\left(10^{-6}\right)$ [s] may be several orders higher in mask projection systems and varies from $\mathcal{O}\left(10^{-6}-10^{-4}\right)[\mathrm{s}]$ in general according to [55].

\subsection{Input-output selection}

The third step in control system design is to select the inputs and outputs, which involves deciding on the number, place and type of the actuators and sensors [147]. The classification scheme presented in Table 2 indicates the number and place and hence the spatial dimensionality of the actuators for different irradiation methods. The same classification scheme can be applied to sensing methods. For realtime feedback control, a match between the number of actuators and sensors seems sensible. Moreover, the spatial resolution required for sensing should approximately match the spatial actuator resolution, since using a too fine spatial sensor resolution is ineffective if the process cannot be actuated at such a fine resolution. An example of how colocated actuation and measurement can be achieved using the same beam steering hardware in vector scanning systems is given in [148].

The controllability of the degree of conversion is limited due to the irreversible nature of polymerization, that is, the degree of conversion can only increase. The photopolymerization reaction continues after irradiation, a phenomenon termed dark reaction $[8,54]$. Nonetheless, it has been shown that the reaction can be terminated by immersing the part in acetone [149]. The observability of the degree of conversion distribution from the temperature distribution was checked by Yebi [63].

Section 4.1.1 outlined several alternative stimuli to initiate the polymerization reaction. The light source's irradiance seems a logical choice for the input. Other variables can be considered as input candidates as well, such as temperature. The coupling between the cure rate and temperature implies that spatial distributions of the degree of conversion can be compensated even further than in Yebi's work by actuating the temperature at the layer boundary. Other input candidates are the oxygen concentration [66] and the light source wavelength to have control over penetration depth [150].

\subsection{Potential control strategy feasibility}

The fourth step in control system design is to select the control configuration, i.e., specifying the interconnections between the inputs and outputs. Suppose the input is the irradiance and the output is the degree of conversion. In vector scanning systems, a single-input singleoutput (SISO) control loop could be closed. In mask projection systems, a set of SISO control loops for each pixel could be defined, or a more complicated multiple-input multiple-output (MIMO) control loop that includes interactions between neighboring pixels.

In evaluating the feasibility of real-time feedback control, a key aspect is to check whether sensing, computation and actuation are fast enough to influence the process. Fig. 27 shows a comparison of the time scales at which the physical phenomena take place, the sampling periods at which the sensing technologies measure, and the time it takes for the actuators to respond.

With respect to vector scanning systems, the figure clearly shows that laser diodes can be modulated fast enough [151] to influence the kinetic reaction, which takes place at least three orders slower. The current sensing technologies, however, are not fast enough for use in real-time feedback control schemes. This implies that either the sampling rates need to be increased, or the process needs to be slowed down by decreasing irradiance values.

With respect to mask projection systems, Fig. 27 reveals that DMDs can switch fast enough [152] to influence the kinetic reaction, since the polymerization rate is limited by the photon flux [8]. Some sensing technologies are fast enough as well to measure the process. Hence, real-time feedback control seems feasible for mask projection systems.

An alternative to real-time control schemes would be to resort to layer-to-layer control schemes. Rather than adjusting the irradiance during photopolymerization, those portions that require a higher degree of conversion can be reirradiated after the entire layer has been photopolymerized in a second corrective pass. Referring to Fig. 1, this type of control strategy can perhaps better be categorized as in-situ defect or fault detection and handling.

\section{Conclusion}

The objective of this paper was to study the feasibility of real-time control strategies for vat photopolymerization of ceramics. To this end,

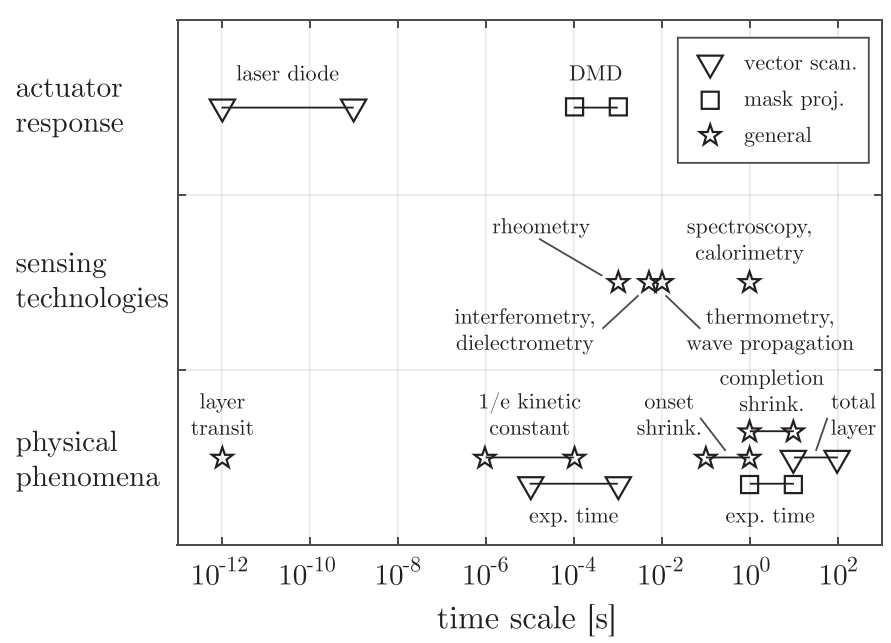

Fig. 27. Time scale comparison of process dynamics, sensing and actuation. 
the state of the art in process control, modelling, actuation, and sensing is reviewed. A considerable amount of process models have been developed, although the majority is not completely applicable to ceramic slurries due to the presence of ceramic particles. In-situ sensors for realtime monitoring and control currently are hardly available, but the measuring principles known from polymer characterization techniques can potentially be utilized in the development of new sensors. The ceramic particles, however, again complicate the use of some of these measurement techniques. Moreover, the temporal and spatial resolutions at which these measurements currently can be obtained, challenge the suitability for use in control loops. Fortunately, actuator response times do not seem to form a limiting factor in the control loop. Based on the literature review, it can be concluded that the field of closed-loop process control for (ceramic) vat photopolymerization is almost completely open, especially regarding the sensing aspect.

\section{Acknowledgements}

This study was funded by the Netherlands Organisation for Applied Scientific Research (TNO) and was carried out within the AMSYSTEMS Center.

\section{References}

[1] Evans J. Seventy ways to make ceramics. J Eur Ceram Soc 2008;28(7):1421-32. http://dx.doi.org/10.1016/j.jeurceramsoc.2007.12.015.

[2] Colombo P, Mera G, Riedel R, Sorarù GD. Polymer-derived ceramics: 40 years of research and innovation in advanced ceramics. J Am Ceram Soc 2010;93(7):1805-37. http://dx.doi.org/10.1111/j.1551-2916.2010.03876.x.

[3] Travitzky N, Bonet A, Dermeik B, Fey T, Filbert-Demut I, Schlier L, et al. Additive manufacturing of ceramic-based materials. Adv Eng Mater 2014;16(6):729-54. http://dx.doi.org/10.1002/adem.201400097.

[4] Deckers J, Vleugels J, Kruth J-P. Additive manufacturing of ceramics: a review. J Ceram Sci Technol 2014;5(4):245-60. http://dx.doi.org/10.4416/JCST201400032.

[5] Zocca A, Colombo P, Gomes CM, Günster J. Additive manufacturing of ceramics: issues, potentialities, and opportunities. J Am Ceram Soc 2015;98(7):1983-2001. http://dx.doi.org/10.1111/jace.13700.

[6] Gibson I, Rosen D, Stucker B. Additive manufacturing technologies. 2nd ed. New York, NY: Springer; 2015. ISBN 978-1-4939-2112-6 978-1-4939-2113-3. http:// link.springer.com/10.1007/978-1-4939-2113-3.

[7] Halloran JW. Ceramic Stereolithography: additive manufacturing for ceramics by photopolymerization. Annu Rev Mater Res 2016;46(1). http://dx.doi.org/10. 1146/annurev-matsci-070115-031841.

[8] Jacobs P. Rapid prototyping \& manufacturing: fundamentals of stereolithography. Dearborn, MI: Society of Manufacturing Engineers; 1992.

[9] Vlasea ML, Lane B, Lopez F, Mekhontsev S, Donmez A. Development of powder bed fusion additive manufacturing test bed for enhanced real-time process control. Proceedings solid freeform fabrication symposium. 2015. p. 527-39.

[10] Hardt D. Modeling and control of manufacturing processes: getting more involved. J Dyn Syst Meas Control 1993;115:291-300. http://web.mit.edu/ mpcl/www/ Papers/24.Hardt.93.pdf.

[11] Huang Y, Leu MC, Mazumder J, Donmez A. Additive manufacturing: current state, future potential, gaps and needs, and recommendations. J Manuf Sci Eng 2015;137(1):014001.

[12] Reutzel EW, Nassar AR. A survey of sensing and control systems for machine and process monitoring of directed-energy, metal-based additive manufacturing. Rapid Prototyping J 2015;21(2):159-67. http://dx.doi.org/10.1108/RPJ-12-2014-0177.

[13] Spears TG, Gold SA. In-process sensing in selective laser melting (SLM) additive manufacturing. Integr Mater Manuf Innovation 2016;5(2):1-25. http://dx.doi.org/ 10.1186/s40192-016-0045-4.

[14] Mani M, Lane B, Donmez A, Feng S, Moylan S, Fesperman R. Measurement science needs for real-time control of additive manufacturing powder bed fusion processes. Tech. Rep. NIST IR 8036. National Institute of Standards and Technology; 2015. http://nvlpubs.nist.gov/nistpubs/ir/2015/NIST.IR.8036.pdf.

[15] Pellegrino J, Makila T, McQueen S, Taylor E. Measurement science roadmap for polymer-based additive manufacturing. Tech. Rep. NIST AMS 100-5. Gaithersburg, MD: National Institute of Standards and Technology; 2016. http://nvlpubs.nist. gov/nistpubs/ams/NIST.AMS.100-5.pdf.

[16] Gentry SP. Factors Affecting the resolution of photopolymerized ceramics. Ann Arbor, MI: University of Michigan; 2012. Ph.D. thesis.

[17] Chartier T. Additive manufacturing to produce complex 3d ceramic parts. J Ceram Sci Technol 2015;6(2):95-104. http://dx.doi.org/10.4416/JCST2014-00040.

[18] Schwentenwein M, Schneider P, Homa J. Lithography-based ceramic manufacturing: a novel technique for additive manufacturing of high-performance ceramics. Adv Sci Technol 2014;88:60-4. http://www.scientific.net/AST.88.60.

[19] Chartier T, Badev A. Rapid prototyping of ceramics. Handbook of advanced ceramics. Elsevier; 2013. p. 489-524. ISBN 978-0-12-385469-8. 10.1016/B978-0-
12-385469-8.00028-9.

[20] Jacobs P. Stereolithography and other RP\&M technologies: from rapid prototyping to rapid tooling. New York: ASME Press; 1996.

[21] Tumbleston JR, Shirvanyants D, Ermoshkin N, Janusziewicz R, Johnson AR, Kelly $\mathrm{D}$, et al. Continuous liquid interface production of $3 \mathrm{~d}$ objects. Science 2015;347(6228):1349-52. http://dx.doi.org/10.1126/science.aaa2397.

[22] Ali Z, Türeyen E, Karpat Y, Çakmakcı M. Fabrication of polymer micro needles for transdermal drug delivery system using DLP based projection stereo-lithography. Procedia CIRP 2016;42:87-90. http://dx.doi.org/10.1016/j.procir.2016.02.194.

[23] Bae C-J, Halloran JW. Influence of residual monomer on cracking in ceramics fabricated by stereolithography: influence of residual monomer on cracking. Int $\mathrm{J}$ Appl Ceram Technol 2011;8(6):1289-95. http://dx.doi.org/10.1111/j.1744-7402. 2010.02578.x.

[24] Mitteramskogler G, Gmeiner R, Felzmann R, Gruber S, Hofstetter C, Stampfl J, et al. Light curing strategies for lithography-based additive manufacturing of customized ceramics. Addit Manuf 2014;1-4:110-8. http://dx.doi.org/10.1016/j. addma.2014.08.003.

[25] Wu T. Theoretical modeling and experimental characterization of stress and crack development in parts manufactured through large area maskless photopolymerization. Atlanta, GA: Georgia Institute of Technology; 2014. Ph.D. thesis https://smartech.gatech.edu/bitstream/handle/1853/54274/WUDISSERTATION-2014.pdf? sequence $=1$.

[26] Bartolo PJ, editor. Stereolithography. Boston, MA: Springer US; 2011.. ISBN 978-0 387-92903-3 978-0-387-92904-0. http://link.springer.com/10.1007/978-0-38792904-0.

[27] Bikas H, Stavropoulos P, Chryssolouris G. Additive manufacturing methods and modelling approaches: a critical review. Int J Adv Manuf Technol 2016;83(14):389-405. http://dx.doi.org/10.1007/s00170-015-7576-2.

[28] Garg A, Tai K, Savalani M. State-of-the-art in empirical modelling of rapid prototyping processes. Rapid Prototyping J 2014;20(2):164-78. http://dx.doi.org/10 1108/RPJ-08-2012-0072.

[29] Kwatny HG, Mablekos VE. The modeling of dynamical processes. 1975 IEEE conference on decision and control including the 14th symposium on adaptive processes. 1975. p. 271-81. http://dx.doi.org/10.1109/CDC.1975.270694.

[30] Limaye A, Rosen D. Quantifying dimensional accuracy of a mask projection micro stereolithography system. Proceedings of the 15th solid freeform fabrication symposium, Austin Texas. 2004. p. 481-92. https://www.researchgate.net/ profile/David_Rosen9/publication/247311262_Quantifying_dimensional_ accuracy_of_a_Mask_Projection_Micro_Stereolithography_System/links/ 540d988f0cf2df04e754e931.pdf.

[31] Sun C, Zhang X. Experimental and numerical investigations on microstereolithography of ceramics. J Appl Phys 2002;92(8):4796-802. http://dx.doi. org/10.1063/1.1503410.

[32] Sun C, Fang N, Wu D, Zhang X. Projection micro-stereolithography using digital micro-mirror dynamic mask. Sens Actuators A: Phys 2005;121(1):113-20. http:// dx.doi.org/10.1016/j.sna.2004.12.011.

[33] Kang H-W, Park JH, Cho D-W. A pixel based solidification model for projection based stereolithography technology. Sens Actuators A: Phys 2012;178:223-9. http://dx.doi.org/10.1016/j.sna.2012.01.016.

[34] Zhou C. Optimized mask image projection for large-area based additive manufacturing process. Los Angeles, CA: University of Southern California; 2011. Ph.D. thesis.

[35] Limaye AS. Multi-objective process planning method for mask projection stereolithography. Atlanta, GA: Georgia Institute of Technology; 2007. Ph.D. thesis http://hdl.handle.net/1853/19717.

[36] Zyzalo JR. Masked projection stereolithography: improvement of the Limaye model for curing single layer medium sized parts. 2008. Ph.D. thesis. http://mro. massey.ac.nz/xmlui/bitstream/handle/10179/849/02whole.pdf? sequence $=1 \&$ isAllowed $=\mathrm{y}$.

[37] Sager B. SLA characterization for surface finish improvement: inverse design methods for process planning. Atlanta, GA: Georgia Institute of Technology; 2006 Ph.D. thesis. http://citeseerx.ist.psu.edu/viewdoc/download?doi = 10.1.1.117. $167 \&$ rep $=$ rep $1 \&$ type $=$ pdf

[38] Puskas JE, Long TE, Storey RF, Shaikh S, Simmons CL, editors. In situ spectroscopy of monomer and polymer synthesis. Boston, MA: Springer US; 2003.. ISBN 978-14613-4935-8 978-1-4615-0125-1. http://link.springer.com/10.1007/978-1-46150125-1.

[39] Goodner MD, Bowman CN. Development of a comprehensive free radical photopolymerization model incorporating heat and mass transfer effects in thick films. Chem Eng Sci 2002;57(5):887-900. http://www.sciencedirect.com/science/ article/pii/S0009250901002871.

[40] Fang N, Sun C, Zhang X. Diffusion-limited photopolymerization in scanning microstereolithography. Appl Phys A 2004;79(8). http://dx.doi.org/10.1007/s00339004-2938-X.

[41] Bertsch A. Study of the spatial resolution of a new 3d microfabrication process: the microstereophotolithography using a dynamic mask-generator technique. J Photochem Photobiol A: Chem 1997;107:275-81. http://ac.els-cdn.com/ S1010603096045856/1-s2.0-S1010603096045856-main.pdf?_tid=e192b02af673-11e5-9de5-00000aacb35e\&; acdnat $=1459341507$ 607f917e5a5e88fc7e0cea57a6ba4fb3.

[42] Miller GA, Gou L, Narayanan V, Scranton AB. Modeling of photobleaching for the photoinitiation of thick polymerization systems. J Polym Sci Part A: Polym Chem 2002;40(6):793-808. http://onlinelibrary.wiley.com/doi/10.1002/pola.10162/ full.

[43] Lajunen LHJ, Peramaki P. Spectrochemical analysis by atomic absorption and emission. 2nd ed Cambridge: Royal Society of Chemistry; 2004. ISBN 978-0- 
85404-624-9. OCLC: ocm57355538.

[44] Sun C, Zhang X. The influences of the material properties on ceramic micro-stereolithography. Sens Actuators A 2002;101(3):364-70. http://www.sciencedirect. com/science/article/pii/S0924424702002649.

[45] Liao H. Stereolithography using compositions containing ceramic powders. University of Toronto; 1997. Ph.D. thesis. http://www.collectionscanada.gc.ca/ obj/s4/f2/dsk2/ftp02/NQ27992.pdf

[46] Griffith ML, Halloran JW. Scattering of ultraviolet radiation in turbid suspensions. J Appl Phys 1997;81(6):2538. http://dx.doi.org/10.1063/1.364311.

[47] Tomeckova V, Halloran JW. Predictive models for the photopolymerization of ceramic suspensions. J Eur Ceram Soc 2010;30(14):2833-40. http://dx.doi.org/ 10.1016/j.jeurceramsoc.2010.01.027.

[48] Brulle Y, Bouchy A, Valance B, André JC. Industrial photochemistry XXI. Chemical, transport and refractive index effects in space-resolved laser photopolymerization. J Photochem Photobiol A: Chem 1994;83(1):29-37. http://www.sciencedirect. com/science/article/pii/1010603094030839.

[49] Schmocker A. Surgical probe and implant development for nucleus pulposus replacements. Lausanne: École Polytechnique Fédérale de Lausanne; 2016. Ph.D. thesis. https://pdfs.semanticscholar.org/aa13/ d1c6e638daf3f714c20df3dd00640c05a81f pdf.

[50] Jariwala AS. Modeling And Process planning for exposure controlled projection lithography. Atlanta, GA: Georgia Institute of Technology; 2013. Ph.D. thesis.

[51] Flach L, Chartoff RP. A process model for nonisothermal photopolymerization with a laser light source. I: Basic model development. Polym Eng Sci 1995;35(6):483-92. http://onlinelibrary.wiley.com/doi/10.1002/pen. $760350605 /$ full.

[52] Jacobs PF. Fundamentals of stereolithography. Solid freeform fabrication symposium proceedings. 1992. p. 196-211.

[53] Gentry SP, Halloran JW. Light scattering in absorbing ceramic suspensions: effect on the width and depth of photopolymerized features. J Eur Ceram Soc 2015;35(6):1895-904. http://dx.doi.org/10.1016/j.jeurceramsoc.2014.12.006.

[54] Tang Y. Stereolithography cure process modeling. Atlanta, GA: Georgia Institute of Technology; 2005. Ph.D. thesis. https://smartech.gatech.edu/handle/1853/7235.

[55] Odian GG. Principles of polymerization. 4th ed Hoboken, N.J: Wiley-Interscience; 2004. ISBN 978-0-471-27400-1. OCLC: ocm53393894.

[56] Koplin C, Gurr M, Mülhaupt R, Jaeger R. Shape accuracy in stereolithography: a material model for the curing behavior of photo-initiated resins. International user's conference on rapid prototyping and rapid tooling and rapid manufacturing (euro-urapid). 2008. p. 315-8. http://www.en.iwm.fraunhofer.de/fileadmin/ media/organisiert-geschaeftsfelder/tribologie/biomed-materialien/pdf/euro urapid2008.pdf.

[57] Flach L, Chartoff RP. A process model for nonisothermal photopolymerization with a laser light source. II: Behavior in the vicinity of a moving exposed region. Polym Eng Sci 1995;35(6):493-8. http://onlinelibrary.wiley.com/doi/10.1002/pen. 760350606 /abstract.

[58] Altun-çiftçioğlu GA. Mathematical Modeling and Simulation of Photopolymerization Process. Istanbul: Istanbul Technical University; 2008. Ph.D. thesis. https://polen.itu.edu.tr/handle/11527/6434

[59] Perry MF, Young GW. A mathematical model for photopolymerization from a stationary laser light source. Macromol Theory Simulat 2005;14(1):26-39. http:// dx.doi.org/10.1002/mats.200400056.

[60] Matias JM. Infrared stereolithography. Braga: University of Minho; 2014. Ph.D. thesis. http://repositorium.sdum.uminho.pt/handle/1822/35457.

[61] Kambly K. Characterization of curing kinetics and polymerization shrinkage in ceramic-loaded photocurable resins for large area maskless photopolymerization (LAMP). Atlanta, GA: Georgia Institute of Technology; 2009. Master's thesis https://smartech.gatech.edu/bitstream/handle/1853/31740/kambly_kiran_ 200912 mast.pdf? sequence $=1$.

[62] Hur SS, Youn JR. Thermal deformation of a photo-cured polymer for the analysis of stereolithography. Polymer-Plastics Technol Eng 2000;39(4):651-66. http://dx. doi.org/10.1081/PPT-100100049.

[63] Yebi AM. Model-based control of UV curing processes with application to additive manufacturing. Clemson, SC: Clemson University; 2015. Ph.D. thesis. http:// gradworks.umi.com/37/22/3722489.html.

[64] Suzuki Y, Tahara H, Michihata M, Takamasu K, Takahashi S. Evanescent Light Exposing System under Nitrogen Purge for nano-stereolithography. Procedia CIRP 2016;42:77-80. http://dx.doi.org/10.1016/j.procir.2016.02.192. http:// linkinghub.elsevier.com/retrieve/pii/S2212827116004765.

[65] Provin C. Microstéréolithographie de céramiques. Nancy: Institut National Polytechnique de Lorraine; 2002. Ph.D. thesis.

[66] Dufaud O, Corbel S. Oxygen diffusion in ceramic suspensions for stereolithography. Chem Eng J 2003;92(1):55-62. http://www.sciencedirect.com/ science/article/pii/S1385894702001158.

[67] Xu Y, Imamura M, Nakagawa T. Microscopic flow observation of photopolymer by UV-laser beam exposure. Solid freeform fabrication symposium proceedings. Center for Materials Science and Engineering, Mechanical Engineering Department and Chemical Engineering Department, the University of Texas at Austin; 1997. p. 177. http://sffsymposium.engr.utexas.edu/Manuscripts/1997/1997-20-Xu.pdf.

[68] Flach L, Chartoff RP. A simple polymer shrinkage model applied to stereolithography. Proceedings of the solid freeform fabrication symposium. DTIC Document; 1994. p. 225-33. http://www.dtic.mil/cgi-bin/GetTRDoc?AD = ADA290949\#page $=234$.

[69] Narahara H, Tanaka F, Kishinami T, Igarashi S, Saito K. Reaction heat effects on initial linear shrinkage and deformation in stereolithography. Rapid Prototyping $\mathrm{J}$ 1999;5(3):120-8. http://dx.doi.org/10.1108/13552549910278946.

[70] Bugeda G, Cervera M, Lombera G, Onate E. Numerical analysis of stereolithography processes using the finite element method. Rapid Prototyping $J$ 1995;1(2):13-23. http://dx.doi.org/10.1108/13552549510086835.

[71] Chambers RS, Guess T, Hinnerichs T. A Phenomenological finite element model o part building in the stereolithography process. Proceedings of the sixth international conference on rapid prototyping. 1995.

[72] Hur SS, Youn JR. Prediction of the deformation in stereolithography products based on elastic thermal shrinkage. Polymer-Plastics Technol Eng 1998;37(4):539-63. http://dx.doi.org/10.1080/03602559808001379.

[73] Huang Y-M, Jiang C-P. Curl distortion analysis during photopolymerisation of stereolithography using dynamic finite element method. Int J Adv Manuf Technol 2003;21(8):586-95. http://link.springer.com/article/10.1007/s00170-002 1317-z.

[74] Vatani M, Barazandeh F, Rahimi A, Sanati Nezhad A. Distortion modeling of SL parts by classical lamination theory. Rapid Prototyping J 2012;18(3):188-93. http://dx.doi.org/10.1108/13552541211218090.

[75] Jiang CP. Development and curing analysis of multi-optical source stereolithography system. Taipei: National Taiwan University of Science and Technology; 2003. Ph.D. thesis.

[76] Eschl J. Die mechanischen Eigenschaften von Stereolithographiematerialien whrend der Aushrtung. Stuttgart: University of Stuttgart; 2002. Ph.D. thesis. http://elib.uni-stuttgart.de/handle/11682/1591.

[77] Koplin C, Jaeger R, Hahn P. Kinetic model for the coupled volumetric and therma behavior of dental composites. Dental Mater 2008;24(8):1017-24. http://dx.doi. org/10.1016/j.dental.2007.11.023. http://linkinghub.elsevier.com/retrieve/pii/ S0109564107002813.

[78] Yasui M, Ikuta K. 3d general photocurable model of resin with various kinds of microparticles. 2013 IEEE 26th international conference on micro electro mechanical systems (MEMS). IEEE; 2013. p. 453-6. http://ieeexplore.ieee.org/xpls/ abs_all.jsp?arnumber $=6474276$

[79] Jelley C, Thompson C. Rapid prototyping simulation: past, present and future1996; https://www.herts.ac.uk/_data/assets/pdf_file/0018/12267/WPD_vol1_jelley thompson.pdf.

[80] Matias JM, Bártolo PJ, Pontes AV. Modeling and simulation of photofabrication processes using unsaturated polyester resins. J Appl Polym Sci 2009;114(6):3673-85. http://dx.doi.org/10.1002/app.30405.

[81] Huang Y-M, Kuriyama S, Jiang C-P. Fundamental study and theoretical analysis in a constrained-surface stereolithography system. Int J Adv Manuf Technol 2004;24(5-6):361-9. http://dx.doi.org/10.1007/s00170-003-1627-9.

[82] Emami MM, Barazandeh F, Yaghmaie F. An analytical model for scanning-projection based stereolithography. J Mater Process Technol 2015;219:17-27. http:/ dx.doi.org/10.1016/j.jmatprotec.2014.12.001.

[83] Hong W, Lee YT, Gong H. Thermal analysis of layer formation in a stepless rapid prototyping process. Appl Thermal Eng 2004;24(2-3):255-68. http://dx.doi.org/ 10.1016/j.applthermaleng.2003.08.015.

[84] Fouassier J-P. Polymerization under light and other external stimuli. Macromolecular engineering: precise synthesis, materials properties, applications. Weinheim: Wiley-VCH; 2007. ISBN 978-3-527-31446-1.

[85] Williams CB, Mistree F, Rosen DW. A functional classification framework for the conceptual design of additive manufacturing technologies. J Mech Des 2011;133(12):121002. http://dx.doi.org/10.1115/1.4005231.

[86] Bartolo P, Mitchell G. Stereothermallithography: a new principle for rapid prototyping. Rapid Prototyping J 2003;9(3):150-6. http://dx.doi.org/10.1108/ 13552540310477454.

[87] Loose K, Niino T, Nakagawa T. Rasterbased exposure through multiple parallel beams in stereolithography. Rapid Prototyping J 1999;5(3):103-11. http://dx.doi. org/10.1108/13552549910278928.

[88] Emami MM, Barazandeh F, Yaghmaie F. Scanning-projection based stereolithography: method and structure. Sens Actuators A: Phys 2014;218:116-24. http://dx.doi.org/10.1016/j.sna.2014.08.002.

[89] Pan Y, Dagli C. Dynamic resolution control in a laser projection-based stereolithography system. Rapid Prototyping J 2017;23(1):190-200. http://dx.doi.org/ 10.1108/RPJ-08-2015-0113.

[90] Zhou C, Ye H, Zhang F. A novel low-cost stereolithography process based on vector scanning and mask projection for high-accuracy, high-speed, high-throughput, and large-area fabrication. J Comput Inf Sci Eng 2015;15(1):011003. http:// medicaldevices.asmedigitalcollection.asme.org/article.aspx?articleid $=1918871$

[91] Reed WF, Alb AM, editors. Monitoring polymerization reactions: from fundamentals to applicationsHoboken, New Jersey: John Wiley \& Sons, Inc; 2014. ISBN 978-0-470-91738-1.

[92] Frauendorfer E, Wolf A, Hergeth W-D. Polymerization online monitoring. Chem Eng Technol 2010;33(11):1767-78. http://dx.doi.org/10.1002/ceat.201000265.

[93] Fonseca GE, Dubé MA, Penlidis A. A critical overview of sensors for monitorin polymerizations. Macromol Reaction Eng 2009;3(7):327-73. http://dx.doi.org/10. 1002/mren.200900024.

[94] Decker C. Photoinitiated crosslinking polymerisation. Prog Polym Sci 1996;21:593-650. http://nathan.instras.com/documentDB/paper-314.pdf.

[95] Zhao X, Rosen DW. Investigation of advanced process control methods for exposure controlled projection lithography. Solid freeform fabrication symposium proceedings. 2014. p. 143-62. http://sffsymposium.engr.utexas.edu/sites/ default/files/2014-014-Zhao.pdf.

[96] Pérez-Juste I, Nieto Faza O. Interaction of radiation with matter. In: Cid r.-M, Bravo J, editors. Structure elucidation in organic chemistry Wiley-VCH Verlag GmbH \& Co. KGaA; 2015. p. 1-26. http://dx.doi.org/10.1002/9783527664610. ch1. ISBN 978-3-527-66461-0.

[97] Scherzer T, Decker U. Real-time FTIRATR spectroscopy to study the kinetics of ultrafast photopolymerization reactions induced by monochromatic UV light. Vib 
Spectrosc 1999;19(2):385-98. http://www.sciencedirect.com/science/article/pii/ S0924203198000708

[98] Osaka K, Kasai A, Kosaka T, Sawada Y. Cure monitoring of UV polymers by Raman spectroscopy. 16th International conference on composite materials. 2007. http:// www.iccm-central.org/Proceedings/ICCM16proceedings/contents/pdf/ThuF/ ThFA2-01ge osakak224422p.pdf.

[99] Michihata M, Takamasu K, Takahashi S. Proposal of in-process measurement for micro-stereolithography using surface plasmon resonance. Phys Procedia 2016;83:964-70. http://dx.doi.org/10.1016/j.phpro.2016.08.101.

[100] Wu KC, Halloran JW. Photopolymerization monitoring of ceramic stereolithography resins by FTIR methods. J Mater Sci 2005;40(1):71-6. http://link. springer.com/article/10.1007/s10853-005-5689-y.

[101] Alabi TR. Design of photomodifiable material systems for maskless patterning of functional ceramic and metallic materials at multiple length scales. 2013. Ph.D. thesis. https://smartech.gatech.edu/handle/1853/51709.

[102] Bower DI, Maddams WF. The vibrational spectroscopy of polymers. 1st pbk ed Cambridge solid state science series Cambridge: Cambridge University Press; 1992. ISBN 978-0-521-24633-0 978-0-521-42195-9.

[103] Cunico MWM, Carvalho JD. Determination of degree of photopolymerization rate by photometric system: application of UV LED and photodiode. Proceedings of COBEM 2011. 2011.

[104] Bernhard P, Hofmann M, Hunziker M. (Interferometric) cure monitoring as a useful tool in the evaluation of resins for stereolithography. Radtech Europe conference proceedings. 1991. Edinburgh.

[105] de Boer J, Visser RJ, Melis GP. Time-resolved determination of volume shrinkage and refractive index change of thin polymer films during photopolymerization. Polymer 1992;33(6):1123-6. http://www.sciencedirect.com/science/article/pii/ $003238619290755 \mathrm{~L}$

[106] Dudi O, Grubbs W. Laser Interferometric technique for measuring polymer cure kinetics. J Appl Polym Sci 1999:74:2133-42.

[107] Schmidt LE. Low stress acrylated hyperbranched polymers. Lausanne: École Polytechnique Fédérale de Lausanne; 2006. Ph.D. thesis. http://citeseerx.ist.psu. edu/viewdoc/download?doi $=10.1 \cdot 1 \cdot 467.9120 \& \mathrm{rep}=$ rep1\&type $=$ pdf

[108] Kostylev I, Labrie D, Price RBT. Time-resolved 2d shrinkage field of dental resins using laser interferometry. Appl Opt 2015;54(7):1852. http://dx.doi.org/10. 1364/AO.54.001852.

[109] Inoue K, Komatsu S, Trinh X-A, Norisuye T, Tran-Cong-Miyata Q. Local deformation in photo-crosslinked polymer blends monitored by Mach-Zehnder interferometry. J Polym Sci Part B: Polym Phys 2005;43(20):2898-913. http://dx doi.org/10.1002/polb.20593.

[110] Jariwala AS, Schwerzel RE, Rosen DW. Real-time interferometric monitoring system for exposure controlled projection lithography. Proceedings of solid freeform fabrication symposium. 2011. p. 99-110. https://www.researchgate.net/ profile/David Rosen9/publication/267599749 Two-Dimensional Real-Time Interferometric Monitoring System for Exposure Controlled Projection Lithography/links/555b21ad08ae6fd2d828f1df.pdf

[111] Zhao X, Rosen DW. Parameter estimation based real-time metrology for exposure controlled projection lithography. Solid freeform fabrication symposium proceedings. 2015. http://sffsymposium.engr.utexas.edu/sites/default/files/2015 2015-104-Zhao.pdf.

[112] Zhao X, Rosen DW. Real-time interferometric monitoring and measuring of photopolymerization based stereolithographic additive manufacturing process: sensor model and algorithm. Meas Sci Technol 2017;28(1):015001. http://dx.doi.org/10. 1088/0957-0233/28/1/015001.

[113] Hoyle CE. Calorimetric analysis of photopolymerization. Radiation curing. Springer; 1992. p. 57-133. http://link.springer.com/chapter/10.1007/978-14899-0712-7_3

[114] Höhne GWH, Hemminger WF, Flammersheim H-J. Differential scanning calorimetry. Berlin, Heidelberg: Springer; 2003. ISBN 978-3-642-05593-5 978-3-66206710-9; http://link.springer.com/10.1007/978-3-662-06710-9.

[115] Brady GA, Halloran JW. Differential photo-calorimetry of photopolymerizable ceramic suspensions. J Mater Sci 1998;33(18):4551-60. http://link.springer.com/ article/10.1023/A:1004416705140

[116] Falk B, Vallinas SM, Zonca MRJ, Crivello JV. Optical pyrometry: a new method for monitoring photopolymerizations. Radtech UV \& EB technical conference proceedings. 2004. http://www.radtechmembers.org/archive-proceedings/2004/ papers/061.pdf.

[117] Xu K. Deformation control for mask image projection based stereolithography process. Los Angeles, CA: University of Southern California; 2016. Ph.D. thesis.

[118] Nicholas JV, White DR. Traceable temperatures: an introduction to temperature measurement and calibration. 2nd ed Chichester: Wiley; 2001. ISBN 978-0-471 49291-7.

[119] May Jr RG. Miniature fiber optic viscoelasticity sensor for composite cure monitoring. Blacksburg (VA): Virginia Polytechnic Institute and State University; 1998. Ph.D. thesis. http://theses.lib.vt.edu/theses/available/etd-61598-91954/.

[120] Zahouily K, Decker C, Kaisersberger E, Gruener M. Real-time UV cure monitoring. Eur Coat J 2003(11):14-34. http://www.european-coatings.com/content/ download/61916/718407/version/1/file/44770.pdf

[121] Xu K, Zhou S, Wu L. On-line and in-real-time monitoring of UV photopolymerization of nanocomposites with microdielectrometry. Prog Org Coat 2009;65(2):237-45. http://dx.doi.org/10.1016/j.porgcoat.2008.11.010.

[122] Steinhaus J, Hausnerova B, Haenel T, Selig D, Duvenbeck F, Moeginger B Correlation of shear and dielectric ion viscosity of dental resins influence of composition, temperature and filler content. Dent Mater 2016;32(7):899-907. http://dx.doi.org/10.1016/j.dental.2016.03.015.

[123] GmbH N.-G. DEA 288 Epsilon Brochure. 2016.

[124] Sheiretov Y, Zahn M. Dielectrometry measurements of spatial moisture profiles in oil-impregnated pressboard. Proceedings of the 4th international conference on properties and applications of dielectric materials. 2. IEEE; 1994. p. 701-4. http:// eeexplore.ieee.org/xpls/abs_all.jsp?arnumber $=414107$

[125] Slopek RP. In-situ monitoring of the mechanical properties during the photopolymerization of acrylate resins using particle tracking microrheology. Atlanta, GA: Georgia Institute of Technology; 2008. Ph.D. thesis. https://smartech.gatech. edu/handle/1853/22657.

[126] Lee SS, Luciani A, Mnson J-AE. A rheological characterisation technique for fast UV-curable systems. Prog Org Coat 2000;38(3):193-7. http://www.sciencedirect. com/science/article/pii/S0300944000000886

[127] Botella A, Dupuy J, Roche A-A, Sautereau H, Verney V. Photo-rheometry/NIR spectrometry: an in situ technique for monitoring conversion and viscoelastic properties during photopolymerization. Macromol Rapid Commun 2004;25(12):1155-8. http://dx.doi.org/10.1002/marc.200400087.

[128] Slopek RP. In-situ monitoring of photopolymerization using microrheology. 2005 Master's thesis. https://smartech gatech.edu/handle/1853/7194.

[129] Hunston D, McDonough W, Fanconi B, Mopsik F, Wang F, Phelan F, et al. Assessment of the state-of-the-art for process monitoring sensors for polymer composites. Tech. Rep. NISTIR 4514. National Institute of Standards and Technology; 1991.

[130] Alig I, Lellinger D, Agarwal S, Oehler H. Monitoring of photopolymerization kinetics and network formation by combined real-time near-infrared spectroscopy and ultrasonic reflectometry. React Funct Polym 2013;73(2):316-22. http://dx. doi.org/10.1016/j.reactfunctpolym.2012.08.006.

[131] Kazilas MC. Acquisition and interpretation of dielectric data for thermoset cure monitoring. Cranfield: Cranfield University; 2003. Ph.D. thesis.

[132] Lionetto F, Maffezzoli A. monitoring the cure state of thermosetting resins by ultrasound. Materials 2013;6(9):3783-804. http://dx.doi.org/10.3390/ma6093783.

[133] Fomitchov PA, Kim YK, Kromine AK, Krishnaswamy S. Laser ultrasonic array system for real-time cure monitoring of polymer-matrix composites. J Compos Mater 2002;36(15):1889-901. http://jcm.sagepub.com/content/36/15/1889. short.

[134] Pan Y. Energy control and material deposition methods for fast fabrication with high surface quality in additive manufacturing using photo-polymerization. Los Angeles, CA: University of Southern California; 2014. Ph.D. thesis.

[135] Chen Z, Li D, Zhou W, Wang L. Curing characteristics of ceramic stereolithography for an aqueous-based silica suspension. Proc Inst Mech Eng, Part B: J Eng Manuf 2010;224(4):641-51. http://dx.doi.org/10.1243/09544054JEM1751.

[136] Chen Z, Li D, Zhou W. Process parameters appraisal of fabricating ceramic parts based on stereolithography using the Taguchi method. Proc Inst Mech Eng, Part B: J Eng Manuf 2012;226(7):1249-58. http://dx.doi.org/10.1177/ 0954405412442607

[137] Rudraraju AV. Digital data processing and computational design for large area maskless photopolymerization. 2013. Ph.D. thesis. https://smartech.gatech.edu/ handle/1853/52930

[138] Zheng X, Deotte J, Alonso MP, Farquar GR, Weisgraber TH, Gemberling S, et al. Design and optimization of a light-emitting diode projection micro-stereolithography three-dimensional manufacturing system. Rev Sci Instrum 2012;83(12):125001. http://dx.doi.org/10.1063/1.4769050.

[139] Shusteff M. Projection Microstereolithography for architected materials. Tech. Rep. Lawrence Livermore National Laboratory; 2015.

[140] Alonso MP. Optimization of a light emitting diode based projection stereolithography system and its applications. University of Illinois at UrbanaChampaign; 2010. Ph.D. thesis. https://www.ideals.illinois.edu/handle/2142/ 16160.

[141] Lee MP, Cooper GJT, Hinkley T, Gibson GM, Padgett MJ, Cronin L. Development of a 3d printer using scanning projection stereolithography. Sci Rep 2015;5:9875. http://dx.doi.org/10.1038/srep09875.

[142] Zhao X, Rosen DW. Process modeling and advanced control methods for exposure controlled projection lithography. American control conference (ACC). IEEE; 2015. p. 3643-8. http://ieeexplore.ieee.org/xpls/abs_all.jsp?arnumber $=$ 7171896

[143] Türeyen EB, Karpat Y, Çakmakcı M. Development of an iterative learning controller for polymer based micro-stereolithography prototyping systems. 2016 American control conference (ACC). IEEE; 2016. p. 852-7. http://ieeexplore.ieee. org/xpls/abs_all.jsp?arnumber $=7525020$

[144] Zhao X, Rosen DW. simulation study on evolutionary cycle to cycle time control of exposure controlled projection lithography. Rapid Prototyping $J$ 2016;22(3):456-64. http://dx.doi.org/10.1108/RPJ-01-2015-0008.

[145] Skogestad S, Postlethwaite I. Multivariable feedback control: analysis and design. 2nd ed New York: Wiley; 2005.

[146] Limaye AS. Design and Analysis of a mask projection micro stereolithography system. 2004. Master's thesis.

[147] van de Wal M, de Jager B. A review of methods for input/output selection. Automatica 2001;37(4):487-510. http://www.sciencedirect.com/science/article/ pii/S0005109800001813.

[148] Craeghs T, Bechmann F, Berumen S, Kruth J-P. Feedback control of layerwise laser melting using optical sensors. Phys Procedia 2010;5:505-14. http://dx.doi.org/ 10.1016/j.phpro. 2010.08.078. 
[149] Li W, Bakhtiary Noodeh M, Delpouve N, Saiter J-M, Tan L, Negahban M. Printing continuously graded interpenetrating polymer networks of acrylate/epoxy by manipulating cationic network formation during stereolithography. Exp Polym Lett 2016;10(12):1003-15. http://dx.doi.org/10.3144/expresspolymlett.2016.93.

[150] Lehtinen P, Laurila S, Kaivola M, Partanen J. Controlling penetration depth in projection stereolithography by adjusting the operation wavelength. Key Eng Mater 2014;611-612:756-62. http://www.scientific.net/KEM.611-612.756.
[151] Sun H. A practical guide to handling laser diode beams. Springer briefs in physics. Dordrecht: Springer Netherlands; 2015. ISBN 978-94-017-9782-5 978-94-0179783-2. http://link.springer.com/10.1007/978-94-017-9783-2.

[152] Dudley D, Duncan WM, Slaughter J. Emerging digital micromirror device (DMD) applications. Micromachining and microfabrication. International Society for Optics and Photonics; 2003. p. 14-25. http://proceedings.spiedigitallibrary.org/ proceeding .aspx? articleid $=893408$. 